\title{
The Origins of the RNA World
}

\author{
Michael P. Robertson and Gerald F. Joyce \\ Departments of Chemistry and Molecular Biology and The Skaggs Institute for Chemical Biology, \\ The Scripps Research Institute, La Jolla, California 92037 \\ Correspondence: gjoyce@scripps.edu
}

\section{SUMMARY}

The general notion of an "RNA World" is that, in the early development of life on the Earth, genetic continuity was assured by the replication of RNA and genetically encoded proteins were not involved as catalysts. There is now strong evidence indicating that an RNA World did indeed exist before DNA- and protein-based life. However, arguments regarding whether life on Earth began with RNA are more tenuous. It might be imagined that all of the components of RNA were available in some prebiotic pool, and that these components assembled into replicating, evolving polynucleotides without the prior existence of any evolved macromolecules. A thorough consideration of this "RNA-first" view of the origin of life must reconcile concerns regarding the intractable mixtures that are obtained in experiments designed to simulate the chemistry of the primitive Earth. Perhaps these concerns will eventually be resolved, and recent experimental findings provide some reason for optimism. However, the problem of the origin of the RNA World is far from being solved, and it is fruitful to consider the alternative possibility that RNA was preceded by some other replicating, evolving molecule, just as DNA and proteins were preceded by RNA.

\section{Outline}

\section{Introduction}

2 An "RNA-first" view of the origin of life

3 An "RNA-later" view of the origin of life

\section{Concluding remarks}

\section{References}

Editors: John F. Atkins, Raymond F. Gesteland, and Thomas R. Cech

Additional Perspectives on RNA Worlds available at www.cshperspectives.org

Copyright (C 2012 Cold Spring Harbor Laboratory Press; all rights reserved; doi: 10.1101/cshperspect.a003608

Cite as Cold Spring Harb Perspect Biol 2012;4:a003608 


\section{INTRODUCTION}

The general idea that, in the development of life on the Earth, evolution based on RNA replication preceded the appearance of protein synthesis was first proposed over 40 yr ago (Woese 1967; Crick 1968; Orgel 1968). It was suggested that catalysts made entirely of RNA are likely to have been important at this early stage in the evolution of life, but the possibility that RNA catalysts might still be present in contemporary organisms was overlooked. The unanticipated discovery of ribozymes (Kruger et al. 1982; GuerrierTakada et al. 1983) initiated extensive discussion of the role of RNA in the origins of life (Sharp 1985; Pace and Marsh 1985; Lewin 1986) and led to the coining of the phrase "the RNA World" (Gilbert 1986).

"The RNA World" means different things to different investigators, so it would be futile to attempt a restrictive definition. All RNA World hypotheses include three basic assumptions: (1) At some time in the evolution of life, genetic continuity was assured by the replication of RNA; (2) Watson-Crick base-pairing was the key to replication; (3) genetically encoded proteins were not involved as catalysts. RNA World hypotheses differ in what they assume about life that may have preceded the RNA World, about the metabolic complexity of the RNA World, and about the role of small-molecule cofactors, possibly including peptides, in the chemistry of the RNA World.

There is now strong evidence indicating that an RNA World did indeed exist on the early Earth. The smoking gun is seen in the structure of the contemporary ribosome (Ban et al. 2000; Wimberly et al. 2000; Yusupov et al. 2001). The active site for peptide-bond formation lies deep within a central core of RNA, whereas proteins decorate the outside of this RNA core and insert narrow fingers into it. No amino acid side chain comes within $18 \AA$ of the active site (Nissen et al. 2000). Clearly, the ribosome is a ribozyme (Steitz and Moore 2003), and it is hard to avoid the conclusion that, as suggested by Crick, "the primitive ribosome could have been made entirely of RNA" (1968).

A more tenuous argument can be made regarding whether life on Earth began with RNA. In what has been referred to as "The Molecular Biologist's Dream" (Joyce and Orgel 1993), one might imagine that all of the components of RNA were available in some prebiotic pool, and that these components could have assembled into replicating, evolving polynucleotides without the prior existence of any evolved macromolecules. However, a thorough consideration of this "RNA-first" view of the origin of life inevitably triggers "The Prebiotic Chemist's Nightmare", with visions of the intractable mixtures that are obtained in experiments designed to simulate the chemistry of the primitive Earth. Perhaps this continuing nightmare will eventually have a happy ending, and recent experimental findings provide some reason for optimism. However, the problem of the origin of the RNA World is far from being solved, and it is fruitful to consider the alternative possibility that RNA was preceded by some other replicating, evolving molecule, just as DNA and proteins were preceded by RNA.

\section{AN "RNA-FIRST" VIEW OF THE ORIGIN OF LIFE}

\subsection{Abiotic Synthesis of Polynucleotides}

This section considers the synthesis of oligonucleotides from $B$-D-nucleoside $5^{\prime}$-phosphates, leaving aside for now the question of how the nucleotides became available on the primitive Earth. Two fundamentally different chemical reactions are involved. First, the nucleotide must be converted to an activated derivative, for example, a nucleoside $5^{\prime}$-polyphosphate. Next the $3^{\prime}$-hydroxyl group of a nucleotide or oligonucleotide molecule must be made to react with the activated phosphate group of a monomer. Synthesis of oligonucleotides from nucleoside $3^{\prime}$-phosphates will not be discussed because activated nucleoside $2^{\prime}-$ or $3^{\prime}$-phosphates in general react readily to form $2^{\prime}, 3^{\prime}$-cyclic phosphates. These cyclic phosphates are unlikely to oligomerize efficiently because the equilibrium constant for dimer formation is only of the order of $1.0 \mathrm{~L} / \mathrm{mol}$ (Erman and Hammes 1966; Mohr and Thach 1969). In the presence of a complementary template somewhat larger oligomers might be formed because the free energy of hybridization would help to drive forward the chain extension reaction.

In enzymatic RNA and DNA synthesis, the nucleoside 5 -triphosphates (NTPs) are the substrates of polymerization. Polynucleotide phosphorylase, although it is a degradative enzyme in nature, can be used to synthesize oligonucleotides from nucleoside $5^{\prime}$-diphosphates. Nucleoside $5^{\prime}$-polyphosphates are, therefore, obvious candidates for the activated forms of nucleotides. Although nucleoside $5^{\prime}$-triphosphates are not formed readily, the synthesis of nucleoside $5^{\prime}$-tetraphosphates from nucleotides and inorganic trimetaphosphate provides a reasonably plausible prebiotic route to activated nucleotides (Lohrmann 1975). Other more or less plausible prebiotic syntheses of nucleoside 5 -polyphosphates from nucleotides have also been reported (Handschuh et al. 1973; Osterberg et al. 1973; Reimann and Zubay 1999). Less clear, however, is how the first phosphate would have been mobilized to convert the nucleosides to 5'-nucleotides. Nucleoside 5'-polyphosphates are high-energy phosphate esters, but are relatively unreactive in aqueous solution. This may be advantageous for enzyme-catalyzed polymerization, but is a severe obstacle for the nonenzymatic polymerization of nucleoside 5 '-polyphosphates, which would occur far more slowly than the hydrolysis of the resulting polynucleotide. 
In a different approach to the activation of nucleotides, the isolation of an activated intermediate is avoided by using a condensing agent such as a carbodiimide (Khorana 1961). This is a popular method in organic synthesis, but its application to prebiotic chemistry is problematic. Potentially prebiotic molecules such as cyanamide and cyanoacetylene activate nucleotides in aqueous solution, but the subsequent condensation reactions are inefficient (Lohrmann and Orgel 1973).

Most attempts to study nonenzymatic polymerization of nucleotides in the context of prebiotic chemistry have used nucleoside $5^{\prime}$-phosphoramidates, particularly nucleoside $5^{\prime}$-phosphorimidazolides. Although phosphorimidazolides can be formed from imidazoles and nucleoside 5 '-polyphosphates (Lohrmann 1977), they are only marginally plausible as prebiotic molecules. They were chosen because they are prepared easily and react at a convenient rate in aqueous solution.

Nucleotides contain three principal nucleophilic groups: the 5'-phosphate, the 2'-hydroxyl, and the 3 '-hydroxyl group, in order of decreasing reactivity. The reaction of a nucleotide or oligonucleotide with an activated nucleotide, therefore, normally yields $5^{\prime}, 5^{\prime}$-pyrophosphate- $2^{\prime}, 5^{\prime}$-phosphodiester-, and $3^{\prime}, 5^{\prime}$-phosphodiester-linked adducts (Fig. 1A), in order of decreasing abundance (Sulston et al. 1968). Thus the condensation of several monomers would likely yield an oligomer containing one pyrophosphate and a preponderance of $2^{\prime}, 5^{\prime}$-phosphodiester linkages (Fig. 1B). There is little chance of producing entirely $3^{\prime}, 5^{\prime}$-linked oligomers from activated nucleotides unless a catalyst can be found that increases the proportion of $3^{\prime}, 5^{\prime}$-phosphodiester linkages. Several metal ions, particularly $\mathrm{Pb}^{2+}$ and $\mathrm{UO}_{2}^{2+}$, catalyze the formation of oligomers from nucleoside $5^{\prime}$-phosphorimidazolides (Sleeper and Orgel 1979; Sawai et al. 1988). The $\mathrm{Pb}^{2+}$-catalyzed reaction is especially efficient when performed in eutectic solutions of the activated monomers (in concentrated solutions obtained by partial freezing of more dilute solutions). Substantial amounts of long oligomers are formed under eutectic conditions, but the product oligomers always contain a large proportion of $2^{\prime}, 5^{\prime}$-linkages (Kanavarioti et al. 2001; Monnard et al. 2003).

What kinds of prebiotically plausible catalysts might lead to the production of $3^{\prime}, 5^{\prime}$-linked oligonucleotides directly from nucleoside $5^{\prime}$-phosphorimidazolides or other activated nucleotides? It is unlikely, but not impossible, that a metal ion or simple acid-base catalyst would provide

A
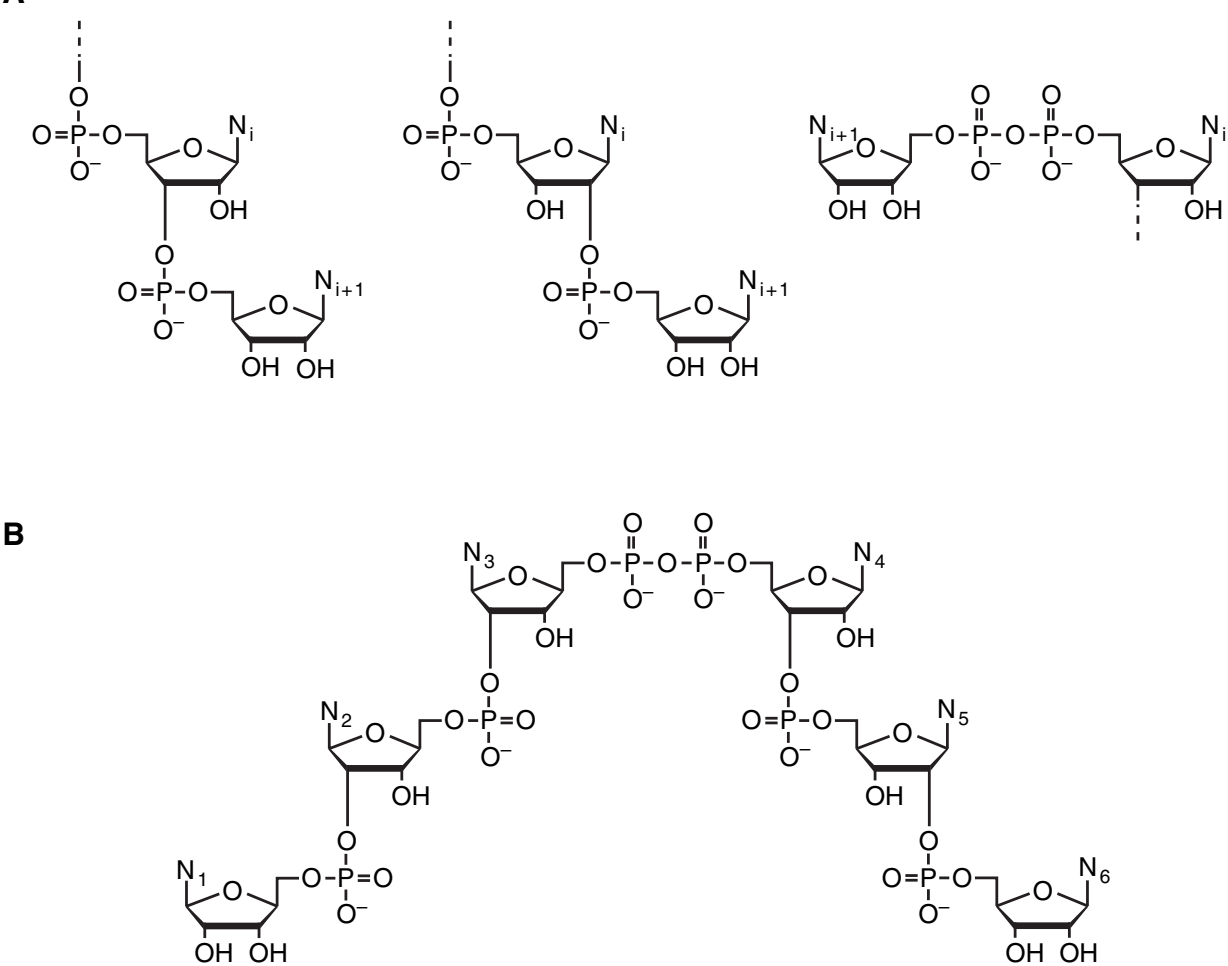

Figure 1. Phosphodiester linkages resulting from chemical condensation of nucleotides. $(A)$ Reaction of an activated mononucleotide $\left(\mathrm{N}_{\mathrm{i}+1}\right)$ with an oligonucleotide $\left(\mathrm{N}_{1}-\mathrm{N}_{\mathrm{i}}\right)$ to form a $3^{\prime}, 5^{\prime}$-phosphodiester (left), 2', $5^{\prime}$-phosphodiester (middle), or 5',5'-pyrophosphate linkage (right). (B) Typical oligomeric product resulting from chemical condensation of activated mononucleotides. 
sufficient regiospecificity. The most attractive of the other hypotheses is that adsorption to a specific surface of a mineral might orient activated nucleotides rigidly and thus catalyze a highly regiospecific reaction.

The work of Ferris and coworkers provides support for this hypothesis (Ferris et al. 2004; Ferris 2006). They have studied the oligomerization of nucleoside $5^{\prime}$-phosphorimidazolides and related activated nucleotides on the clay mineral montmorillonite (Ferris and Ertem 1993; Kawamura and Ferris 1994; Miyakawa and Ferris 2003). Some samples of the mineral are effective catalysts, promoting the formation of oligomers even from dilute solutions of activated nucleotide substrates. Furthermore, the mineral profoundly affects the regiospecificity of the reaction. The oligomerization of adenosine 5'-phosphorimidazolide, for example, gives predominantly $3^{\prime}, 5^{\prime}$-linked products in the presence of montmorillonite, but predominantly $2^{\prime}, 5^{\prime}-$ linked products in aqueous solution (Ding et al. 1996; Kawamura and Ferris 1999). Once short oligomers have been synthesized, they can be further extended by adsorbing them on either montmorillonite or hydroxylapatite and repeatedly adding activated monomers, resulting in the accumulation of mainly $3^{\prime}, 5^{\prime}$-linked oligoadenylates up to 40-50 subunits in length (Ferris et al. 1996; Ferris 2002). However, even when adsorbed on montmorillonite, the phosphorimidazolides of the pyrimidine nucleosides yield oligomers that are predominantly $2^{\prime}, 5^{\prime}$-linked.

Long oligomers have also been obtained from monomers in a single step using a different activated nucleotide in which imidazole is replaced by 1-methyl-adenine (Prabahar and Ferris 1997; Huang and Ferris 2003). Using the 1-methyl-adenine derivative of adenylate or uridylate, oligomers containing up to 40 subunits were produced, consisting of $\sim 75 \% 3^{\prime}, 5^{\prime}$-linkages for oligoadenylate and $\sim 60 \%$ $3^{\prime}, 5^{\prime}$-linkages for oligouridylate (Huang and Ferris 2006). Oligomerization of the 1-methyl-adenine derivative of guanylate or cytidylate was less efficient, but all four activated monomers could be co-incorporated, to at least a modest extent, within abiotically synthesized oligonucleotides.

Detailed analysis of this work on catalysis by montmorillonite suggests that oligomerization occurs at a limited number of structurally specific active sites within the interlayers of the clay (Wang and Ferris 2001). These sites must not be saturated with sodium ions, which appear to block access of the activated nucleotides (Joshi et al. 2009). Several different samples of montmorillonite have proven to be good catalysts, in part depending on their proton versus sodium ion content. It will be important to determine if there are other types of minerals that are comparably efficient catalysts of oligonucleotide synthesis, and if so, to study the regiospecificity and sequence generality of the reactions they catalyze.

\subsection{Nonenzymatic Replication of RNA}

If a mechanism existed on the primitive Earth for the polymerization of activated nucleotides, it would have generated a complex mixture of product oligonucleotides that differed in both length and sequence. The next stage in the emergence of an RNAWorld would have been the replication of some of these molecules, so that a process equivalent to natural selection could begin. The reaction central to replication of nucleic acids is template-directed synthesis, that is, the synthesis of a complementary oligonucleotide under the direction of a preexisting oligonucleotide. A good deal of work has already been performed on this aspect of nonenzymatic replication. This work has been reviewed elsewhere (Joyce 1987; Orgel 2004a), so only a summary of the results will be given here.

The first major conclusion is that most activated nucleotides do not undergo efficient, regiospecific, templatedirected reactions in the presence of an RNA or DNA template. In general, only a small proportion of template molecules succeed in directing the synthesis of a complete complement, and the complement usually contains a mixture of $2^{\prime}, 5^{\prime}$ - and $3^{\prime}, 5^{\prime}$-phosphodiester linkages. After a considerable search, a set of activated nucleotides was found that undergo efficient and highly regiospecific templatedirected reactions. Working with guanosine $5^{\prime}$-phospho-2methylimidazolide (2-MeImpG), it was shown that poly $(C)$ can direct the synthesis of long oligo $(G)$ s in a reaction that is highly efficient and highly regiospecific (Inoue and Orgel 1981). If poly(C) is incubated with an equimolar mixture of the four 2-MeImpNs $(N=G, A, C$, or $\mathrm{U})$, less than $1 \%$ of the product consists of noncomplementary nucleotides (Inoue and Orgel 1982). Subsequent experiments suggested that this and the related reactions discussed later occur preferentially within the context of double helices that have a structure resembling the A form of RNA (Kurz et al. 1997, 1998; Kozlov et al. 1999, 2000).

Random copolymers containing an excess of $\mathrm{C}$ residues can be used to direct the synthesis of products containing $\mathrm{G}$ and the complements of the other bases present in the template (Inoue and Orgel 1983). The reaction with a poly $(C, G)$ template is especially interesting because the products, like the template, are composed entirely of $\mathrm{C}$ and $\mathrm{G}$ residues. If these products in turn could be used as templates, it might allow the emergence of a self-replicating sequence. Self-replication, however, is unlikely, mainly because poly $(\mathrm{C}, \mathrm{G})$ molecules that do not contain an excess of $\mathrm{C}$ residues tend to form stable self-structures that prevent them from acting as templates (Joyce and Orgel 1986). The self-structures are of two types: (1) the standard Watson-Crick variety based on $\mathrm{C} \bullet \mathrm{G}$ pairs, and (2) a quadrahelix structure that results from the association of four 
G-rich sequences. As a consequence, any C-rich oligonucleotide that can serve as a good template will give rise to G-rich complementary products that tend to be locked in self-structure and so cannot act as templates. Overcoming the self-structure problem using the standard C and $\mathrm{G}$ nucleotides is very difficult because it requires the discovery of conditions that favor the binding of mononucleotides to allow template-directed synthesis to occur, but suppress the formation of long duplex regions that would exclude activated monomers from the template.

Some progress has been made in discovering definedsequence templates that are copied faithfully to yield complementary products (Inoue et al. 1984; Acevedo and Orgel 1987; Wu and Orgel 1992a). Successful templates typically contain an excess of $C$ residues, with $A$ and $U$ residues isolated from each other by at least three $\mathrm{C}$ residues. Runs of $\mathrm{G}$ residues are copied into runs of $\mathrm{C}$ residues, so long as the formation of self-structures by $\mathrm{G}$ residues can be avoided ( $\mathrm{Wu}$ and Orgel 1992b). In light of the available evidence, it seems unlikely that a pair of complementary sequences can be found, each of which facilitates the synthesis of the other using nucleoside $5^{\prime}$-phospho-2methylimidazolides as substrates. Some of the obstacles to self-replication may be attributable to the choice of reagents and reaction conditions, but others seem to be intrinsic to the template-directed condensation of activated mononucleotides.

A related nonenzymatic replication scheme involves synthesis by the ligation of short $3^{\prime}, 5^{\prime}$-linked oligomers (James and Ellington 1999). This is certainly an attractive possibility, made more plausible by the discovery of analogous ribozyme-catalyzed reactions (Bartel and Szostak 1993), but it faces two major obstacles. The first is the difficulty of obtaining the substrates in the first place. The second is concerned with fidelity. Pairs of oligonucleotides containing a single base mismatch, particularly if the mismatch forms a $\mathrm{G} \bullet \mathrm{U}$ wobble pair, still hybridize as efficiently as fully complementary oligomers, except in a temperature range very close to the melting point of the perfectly paired structure. Maintaining fidelity would therefore be difficult under any plausible temperature regime.

Despite these problems, template-directed ligation of short oligonucleotides may be a viable alternative to the oligomerization of activated monomers. Ferris' work discussed above suggests that predominantly $3^{\prime}, 5^{\prime}$-linked oligonucleotides might form spontaneously from activated nucleotides on some variety of montmorillonite (Ferris et al. 1996) or on some other mineral. Oligonucleotide $5^{\prime}$-triphosphates undergo slow but remarkably $3^{\prime}, 5^{\prime}$-regiospecific ligation in the presence of a complementary template (Rohatgi et al. 1996a,b). The combination of some such pair of reactions might provide a replication scheme for polynucleotides starting with an input of activated monomers.

There also are efforts in what is sometimes termed "synthetic biology" to achieve nonenzymatic replication with molecules that resemble biological nucleic acids, but are not constrained by considerations of plausible prebiotic chemistry. For example, the 2'- and 3'-hydroxyl groups of activated mononucleotides can be replaced by an amino group at either position, providing enhanced nucleophilicity and resulting in more rapid template-dependent (and template-independent) oligomerization (Lohrmann and Orgel 1976; Zielinski and Orgel 1985). Dinucleotide building blocks, consisting of $3^{\prime}$-amino, $3^{\prime}$-deoxynucleotide analogs can also be oligomerized in the presence of a suitable condensing agent (Zielinski and Orgel 1987). With additional modification of the nucleotide bases, it has been possible to carry out the template-directed copying of nucleic acid sequences that contain of all four bases (Schrum et al. 2009). These efforts, although not explaining the origin of the RNAWorld, contribute to understanding the chemical challenges that must be overcome in achieving the nonenzymatic replication of RNA.

\subsection{The First RNA Replicase}

The notion of the RNAWorld places emphasis on an RNA molecule that catalyzes its own replication. Such a molecule must function as an RNA-dependent RNA polymerase, acting on itself (or copies of itself) to produce complementary RNAs, and acting on the complementary RNAs to produce additional copies of itself. The efficiency and fidelity of this process must be sufficient to produce viable "progeny" RNA molecules at a rate that exceeds the rate of decomposition of the "parents." Beyond these requirements, the details of the replication process are not highly constrained.

The RNA-first view of the origin of life assumes that a supply of activated B-D-nucleotides was available by some as yet unrecognized abiotic process. Furthermore, it assumes that a means existed to convert the activated nucleotides to an ensemble of random-sequence polynucleotides, a subset of which had the ability to replicate. It seems to be implicit in the model that such polynucleotides replicate themselves but, for whatever reason, do not replicate unrelated neighbors. It is not clear whether replication involves one molecule copying itself (and its complement) or a family of molecules that together copy each other. These questions are set aside for the moment in order to first consider the question of whether an RNA molecule of reasonably short length can catalyze its own replication with sufficiently high fidelity. 
Accuracy and Survival. The concept of an error threshold, that is, an upper limit to the frequency of copying errors that can be tolerated by a replicating macromolecule, was first introduced by Eigen (1971). This important idea has been extended in a series of mathematically sophisticated papers by McCaskill, Schuster, and others (McCaskill 1984a; Eigen et al. 1988; Schuster and Swetina 1988). Here only a brief summary of the subject is provided.

Eigen's model (1971) envisages a population of replicating polynucleotides that draw on a limited supply of activated mononucleotides to produce additional copies of themselves. In this model, the rate of synthesis of new copies of a particular replicating RNA is proportional to its concentration, resulting in autocatalytic growth. The net rate of production is the difference between the rate of formation of error-free copies and the rate of decomposition of existing copies of the RNA. For an advantageous RNA to outgrow its competitors, its net rate of production must exceed the mean rate of production of all other RNAs in the population. Only the error-free copies of the advantageous RNA contribute to its net rate of production, but all the copies of the other RNAs contribute to their collective production. Thus the relative advantage enjoyed by the advantageous individual compared with the rest of the population (often referred to as the "superiority" of the advantageous individual) must exceed the probability of producing an error copy of that advantageous individual.

The proportion of copies of an RNA that are error free is determined by the fidelity of the component condensation reactions that are required to produce a complete copy. For simplicity, consider a self-replicating RNA that is formed by $n$ condensation reactions, each having mean fidelity $q$. The probability of obtaining a completely errorfree copy is given by $q^{n}$, which is the product of the fidelity of the component condensation reactions. If an advantageous individual is to outgrow its competitors, $q^{n}$ must exceed the superiority, $s$, of that individual. Expressed in terms of the number of reactions required to produce the advantageous individual,

$$
n<|\ln s| /|\ln q|
$$

For $s>1$ and $q>0.9$, this equation simplifies to

$$
n<\ln s /(1-q)
$$

This is the "error threshold," which describes the inverse relationship between the fidelity of replication, $q$, and the maximum allowable number of component condensation reactions, $n$. The maximum number of component reactions is highly sensitive to the fidelity of replication, but depends only weakly on the superiority of the advantageous individual. For a self-replicating RNA that is formed by the template-directed condensation of activated mononucleotides, a total of $2 n-2$ condensation reactions are required to produce a complete copy. This takes into account the synthesis of both a complementary strand and a complement of the complement.

It should be recognized that a marked superiority of one sequence over all other sequences could not be maintained over evolutionary time because novel variants would soon arise to challenge the dominant species. However, a marked initial superiority may be important in allowing an efficient self-replicating RNA to emerge from a pool of less efficient replicators. In the absence of other efficient replicators, a primitive self-replicating RNA that operates with low fidelity may gain a foothold by taking advantage of a somewhat less stringent error threshold. Whether or not this can occur depends on its superiority. For example, an RNA that replicates 10 -fold more efficiently than its competitors and does so with $90 \%$ fidelity could be no longer than 12 nucleotides, and a similarly advantageous RNA that replicates with $70 \%$ fidelity could be no longer than four nucleotides. It seems highly unlikely than any of the 17 million possible RNA dodecamers is able to catalyze its own replication with $90 \%$ fidelity, and even less likely that a tetranucleotide could catalyze its own replication with $70 \%$ fidelity. However, an RNA that replicates $10^{6}$-fold more efficiently than its competitors and does so with $90 \%$ fidelity could be as long as 67 nucleotides, and one that replicates with $70 \%$ fidelity could be as long as 20 nucleotides.

When self-replication is first established, fidelity is likely to be poor and there is strong selection pressure favoring improvement of the fidelity. As fidelity improves, a larger genome can be maintained. This allows exploration of a larger number of possible sequences, some of which may lead to further improvement in fidelity, which in turn allows a still larger genome size, and so on. Once the evolving population has achieved a fidelity of about $99 \%$, a genome length of about 100 nucleotides can be maintained, even for modest superiority values. This would allow RNA-based life to become firmly established. Until that time, it is a race between evolutionary improvement in the context of a sloppy self-replicating system and the risk of delocalization of the genetic information because of overstepping the error threshold. If the time required to bootstrap to high fidelity and large genomes is too long, there is a risk that the population will succumb to an environmental catastrophe before it has had the chance to develop appropriate countermeasures.

It is difficult to state with certainty the minimum possible size of an RNA replicase ribozyme. An RNA consisting 
of a single secondary structural element, that is, a small stem-loop containing 12-17 nucleotides, would not be expected to have replicase activity, whereas a double stemloop, perhaps forming a "dumbbell" structure or a pseudoknot, might just be capable of a low level of activity. A triple stem-loop structure, containing 40-60 nucleotides, offers a reasonable hope of functioning as a replicase ribozyme. One could, for example, imagine a molecule consisting of a pseudoknot and a pendant stem-loop that forms a cleft for template-dependent replication.

Suppose there is some 40-mer that enjoys a superiority of $10^{3}$-fold and replicates with $90 \%$ fidelity. This should be regarded as a highly optimistic but not outrageous view of what is possible for a minimum replicase ribozyme. Would such a molecule be expected to occur within a population of random-sequence RNAs? A complete library consisting of one copy each of all $10^{24}$ possible 40 -mers would weigh about $1 \mathrm{~kg}$. There may be many such 40-mers, encompassing both distinct structural motifs and, more importantly, a large number of equivalent representations of each motif. As a result, even a small fraction of the total library, consisting of perhaps $10^{20}$ sequences and weighing about $1 \mathrm{~g}$, might be expected to contain at least one self-replicating RNA with the requisite properties. It is not sufficient, however, that there be just one copy of a self-replicating RNA. The above calculations assume that a self-replicating RNA can copy itself (or that a fully complementary sequence is automatically available, as will be discussed later). If two or more copies of the same 40mer RNA are needed, then a much larger library, consisting of $10^{48}$ RNAs and weighing $10^{28} \mathrm{~g}$ would be required. This amount is comparable to the mass of the Earth.

At first sight, it might seem that one way to ease the error threshold would be for the replicase ribozyme to accept dinucleotide or trinucleotide substrates, so that copies of the RNA could be formed by fewer condensation reactions. Calculations show that, over a broad range of superiority values, RNAs that are required to replicate with $90 \%$ fidelity when using mononucleotide substrates would be required to replicate with roughly $80 \%$ fidelity when using dinucleotide substrates or roughly $70 \%$ fidelity when using trinucleotide substrates. Thus the use of short oligomers offers only a modest advantage because of lessening of the error threshold, which likely would be outweighed by the greater difficulty of achieving high fidelity when discriminating among the 16 possible dinucleotide or 64 possible trinucleotide substrates, rather than among the four mononucleotides.

If one accepts the RNA-first view that there was a prebiotic pool of random-sequence RNAs, and if one assumes that the pool included a replicase ribozyme containing, say, 40 nucleotides and replicating itself with about $90 \%$ fidelity, then it is not difficult to imagine how RNA-based evolution might have started. During the initial period a successful clone would have expanded in the absence of competition. As competition for substrates intensified there would have followed a succession of increasingly more advantageous individuals, each replicating within its error threshold. After a period of intensifying competition, the single most advantageous species would have been replaced by a "quasispecies," that is, a mixture of the most advantageous individual and substantial amounts of closely related individuals that replicate almost as fast and almost as faithfully as the most advantageous one (Eigen and Schuster 1977; Eigen et al. 1988). Under these conditions the persistence of a particular advantageous individual is no longer the problem, but one must understand the evolution of the composition of the quasispecies and the conditions for its persistence. This difficult problem has been partially solved by McCaskill (1984b). The general form of the solution is very similar to the error threshold described by Eigen (1971), but with different values for the constant in the inequality. Thus concerns about the error threshold apply to the quasispecies as well as to the succession of individuals. Practically speaking, however, once a quasispecies distribution of sophisticated replicators had emerged, the RNA World would have been on solid footing and, barring an environmental catastrophe, unlikely to lose the ability to maintain genetic information over time.

Another Chicken-and-Egg Paradox. The previous discussion has tried mightily to present the most optimistic view possible for the emergence of an RNA replicase ribozyme from a soup of random-sequence polynucleotides. It must be admitted, however, that this model does not appear to be very plausible. The discussion has focused on a straw man: The myth of a small RNA molecule that arises de novo and can replicate efficiently and with high fidelity under plausible prebiotic conditions. Not only is such a notion unrealistic in light of current understanding of prebiotic chemistry (Joyce 2002), but it should strain the credulity of even an optimist's view of RNA's catalytic potential. If you doubt this, ask yourself whether you believe that a replicase ribozyme would arise in a solution containing nucleoside $5^{\prime}$-diphosphates and polynucleotide phosphorylase!

If one accepts the notion of an RNAWorld, one is faced with the dilemma of how such a genetic system came into existence. To say that the RNAWorld hypothesis "solves the paradox of the chicken-and-the-egg" is correct if one means that RNA can function both as a genetic molecule and as a catalyst that promotes its own replication. RNAcatalyzed RNA replication provides a chemical basis for 
Darwinian evolution based on natural selection. Darwinian evolution is a powerful way to search among vast numbers of potential solutions for those that best address a particular problem. Selection based on inefficient RNA replication, for example, could be used to search among a population of RNA molecules for those individuals that promote improved RNA replication. But here one encounters another chicken-and-egg paradox: Without evolution it appears unlikely that a self-replicating ribozyme could arise, but without some form of self-replication there is no way to conduct an evolutionary search for the first, primitive self-replicating ribozyme.

One way that RNA evolution may have gotten started without the aid of an evolved catalyst might be by using nonenzymatic template-directed synthesis to permit some copying of RNA before the appearance of the first replicase ribozyme. Suppose that the initial ensemble of monomers was not produced by random copolymerization, but rather by a sequence of untemplated and templated reactions (Fig. 2), and further suppose that members of the initial ensemble of multiple stem-loop structures could be replicated, albeit inefficiently, by the template-directed process. This would have two important consequences. First, any molecule with replicase function that appeared in the mixture would likely find in its neighborhood similar molecules and their complements, related by descent, thus eliminating the requirement for two unrelated replicases to meet. Second, a majority of molecules in the mixture would contain stem-loop structures. If it is true that ribozyme function is favored by stable self-structure, and if the base-sequences of the stems in stem-loop structures are relatively unimportant for function, this model might provide an economical way of generating a relatively small ensemble of sequences that is enriched with catalytic sequences.

How plausible is the assumption that replicases could act on sequences similar to themselves, while ignoring unrelated sequences? This selectivity could be ensured by segregating individual molecules (or clonal lines) on the surface of mineral grains, on the surface of micelles, or within membranes. Closely related molecules might be segregated as a group through specific hydrogen-bonding interactions (the family that sticks together, replicates together). For any segregation mechanism, weak selection would result if the replicating molecules are sufficiently dispersed that diffusion over their intermolecular distance is slow compared with replication. Computer simulations have shown that under such conditions of segregation, evolutionary bootstrapping can occur, resulting in progressively larger genomes that are copied with progressively greater fidelity (Szabó et al. 2002). Alternatively, the
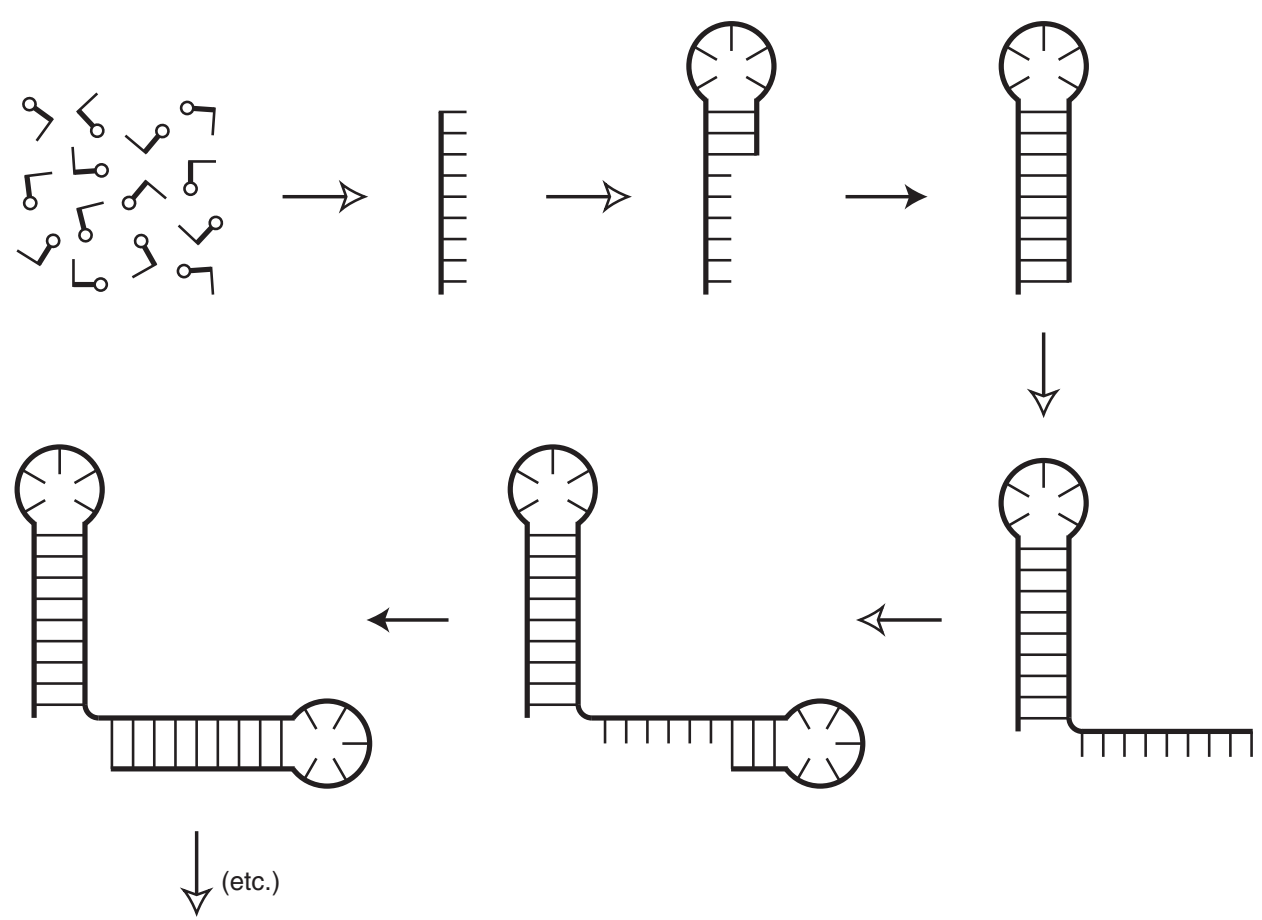

Figure 2. Nonenzymatic synthesis of multi-stem-loop structures as a result of untemplated (open arrowhead) and templated (filled arrowhead) reactions. Template-directed synthesis is assumed to occur rapidly whenever a template, activated monomers, and a suitable primer are available. Once the complementary strand is completed, additional residues are added slowly in a random-sequence manner. 
requirement for replication of related, but not unrelated, sequences might be met through the use of "genomic tags" (Weiner and Maizels 1987). Among self-replicating sequences, it is plausible that some are restricted to copying molecules with a particular $3^{\prime}$-terminal subsequence. A replicator that happened by chance to carry a terminal sequence that matched the preference of its active site would replicate itself while ignoring its neighbors.

Another resolution of the paradox of how RNA evolution was initiated without the aid of an evolved ribozyme is to abandon the RNA-first view of the origin of life and suppose that RNA was not the first genetic molecule (Cairns-Smith 1982; Shapiro 1984; Joyce et al. 1987; Joyce 1989, 2002; Orgel 1989, 2004a). Perhaps RNA replication arose in the context of an evolving system based on something other than RNA (see the section "Alternative Genetic Systems"). Even if this is true, all of the arguments concerning the relationship between the fidelity of replication and the maximum allowable genome length would still apply to this earlier genetic system. Of course, the challenge to those who advocate the RNA-later approach is to show that there is an informational entity that is prebiotically plausible and is capable of initiating its own replication without the aid of a sophisticated catalyst.

\subsection{Replicase Function in the Evolved RNA World}

Although it is difficult to say how the first RNA replicase ribozyme arose, it is not difficult to imagine how such a molecule, once developed, would function. The chemistry of RNA replication would involve the template-directed polymerization of mono- or short oligonucleotides, using chemistry in many ways similar to that used by contemporary group I ribozymes (Cech 1986; Been and Cech 1988; Doudna and Szostak 1989). One important difference is that, unlike group I ribozymes, which rely on a nucleoside or oligonucleotide leaving group, an RNA replicase would more likely make use of a different leaving group that provides a substantial driving force for polymerization and that, after its release, does not become involved in some competing phosphoester transfer reaction.

From Ligases to Polymerases. The polymerization of activated nucleotides proceeds via nucleophilic attack by the $3^{\prime}$-hydroxyl of a template-bound oligonucleotide at the $\alpha$-phosphorus of an adjacent template-bound nucleotide derivative (Fig. 3). The nucleotide is "activated" for attack by the presence of a phosphoryl substituent, for example a phosphate, polyphosphate, alkoxide, or imidazole group. As discussed previously, polyphosphates, such as inorganic pyrophosphate, are the most obvious candidates for the leaving group. The condensation reaction could be assisted

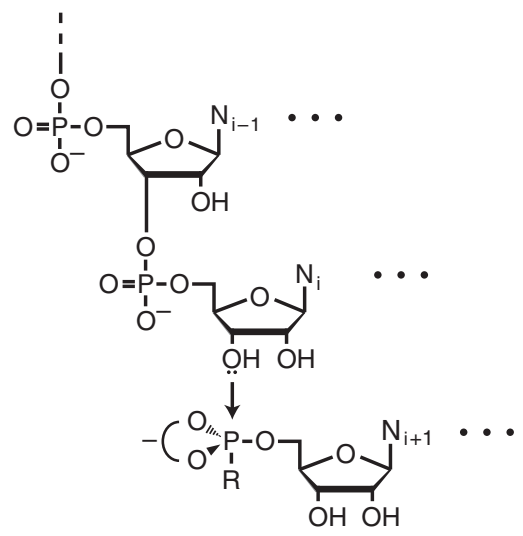

Figure 3. Nucleophilic attack by the $3^{\prime}$-hydroxyl of a template-bound oligonucleotide $\left(\mathrm{N}_{1}-\mathrm{N}_{\mathrm{i}}\right)$ on the $\alpha$-phosphorus of an adjacent template-bound mononucleotide $\left(\mathrm{N}_{\mathrm{i}+1}\right)$. Dotted lines indicate base pairing to a complementary template. $\mathrm{R}$ is the leaving group.

by favorable orientation of the reactive groups, deprotonation of the nucleophilic $3^{\prime}$-hydroxyl, stabilization of the trigonal-bipyramidal transition state, and charge neutralization of the leaving group. All of these tasks might be performed by RNA (Narlikar and Herschlag 1997; Emilsson et al. 2003), acting either alone (Ortoleva-Donnelly and Strobel 1999) or with the help of a suitably positioned metal cation or other cofactor (Shan et al. 1999; Shan et al. 2001).

The possibility that an RNA replicase ribozyme could have existed has been made abundantly clear by work involving ribozymes that have been developed in the laboratory through in vitro evolution (Bartel and Szostak 1993; Ekland et al. 1995; Ekland and Bartel 1996; Robertson and Ellington 1999; Jaeger et al. 1999; Rogers and Joyce 2001; Johnston et al. 2001; McGinness and Joyce 2002; Ikawa et al. 2004; Fujita et al. 2009). Bartel and Szostak (1993), for example, began with a large population of random-sequence RNAs and evolved the "class I" RNA ligase ribozyme, an optimized version of which is about 100 nucleotides in length and catalyzes the joining of two template-bound oligonucleotides. Condensation occurs between the $3^{\prime}$-hydroxyl of one oligonucleotide and the $5^{\prime}$-triphosphate of another, forming a $3^{\prime}, 5^{\prime}$-phosphodiester linkage and releasing inorganic pyrophosphate. This reaction is classified as ligation because of the nature of the oligonucleotide substrates, but involves the same chemical transformation as is catalyzed by modern RNA polymerase enzymes.

X-ray crystal structures of two RNA ligase ribozymes, the $\mathrm{L} 1$ and above-mentioned class I ligases, have been determined, providing a glimpse into the mechanistic strategies that these two structurally and evolutionarily distinct ribozymes use to catalyze the same reaction (Robertson and 


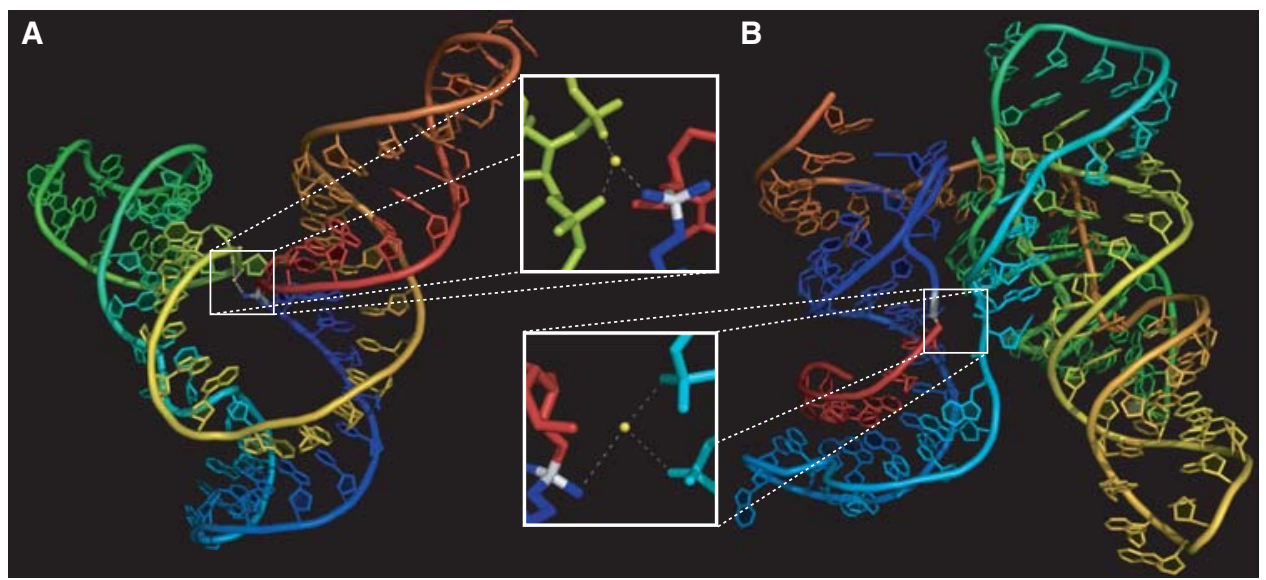

Figure 4. X-ray crystal structure of the $(A)$ L1 ligase and $(B)$ class I ligase ribozymes. Insets show the putative magnesium ion binding sites at the respective ligation junctions. The structures are rendered in rainbow continuum, with the $5^{\prime}$-triphosphate-bearing end of the ribozyme colored violet and the $3^{\prime}$-hydroxyl-bearing end of the substrate colored red. The phosphate at the ligation junction is shown in white, and the proximate magnesium ion (modeled for the class I ligase) is shown as a yellow sphere, with dashed lines indicating coordination contacts.

Scott 2007; Shechner et al. 2009) (Fig. 4). Both crystal structures capture the product of the ligation reaction, and consequently offer an incomplete view of the reaction pathway. For example, the pyrophosphate leaving group is absent from the structures, so no conclusions can be drawn regarding potential ribozyme-assisted orientation of the reactive triphosphate or charge neutralization of the pyrophosphate leaving group. There is, however, information regarding other aspects of the reaction mechanism that can be inferred from the product structures.

Both the L1 and class I ligases are dependent on the presence of magnesium ions for their activity. A prominent feature of the L1 structure (Fig. 4A) involves a bound metal ion in the active site, coordinated by three nonbridging phosphate oxygens, one of which belongs to the newly formed phosphodiester linking what originally were the two substrates. This magnesium ion is favorably positioned to help neutralize the increased negative charge of the transition state and, potentially, to activate the $3^{\prime}$-hydroxyl nucleophile and to help orient the $\alpha$-phosphate for a more optimal in-line alignment. In the case of the class I structure (Fig. 4B), no catalytic metal ions appear to have been retained in the vicinity of the active site, although two magnesium ions are observed to participate in crucial structural interactions that help shape the active site architecture. Despite the lack of direct observation of a catalytic metal at the active site, there is what appears to be an empty metal binding site formed by two nonbridging phosphate oxygens, positioned directly opposite the ligation junction in a manner similar to that observed for the magnesium binding site of the L1 ligase and reminiscent of the arrangement seen in protein polymerases. The lack of a metal in the crystal structure may simply be an artifact of the crystallization process or may imply a local conformational change in the product that disfavors retention of the bound metal. These structures show that, despite some remaining gaps in the detailed understanding of how these ribozymes function, the available information points to a universal catalytic strategy, very similar to that used by modern protein-based RNA polymerases.

Subsequent to its isolation as a ligase, the class I ribozyme was shown to catalyze a polymerization reaction in which the $5^{\prime}$-triphosphate-bearing oligonucleotide is replaced by one or more NTPs (Ekland and Bartel 1996). This reaction proceeds with high fidelity $(q=0.92)$, but the reaction rate drops sharply with successive nucleotide additions.

Bartel and colleagues performed further in vitro evolution experiments to convert the class I ligase to a bona fide RNA polymerase that operates on a separate RNA template (Johnston et al. 2001). To the $3^{\prime}$ end of the class I ligase they added 76 random-sequence nucleotides that were evolved to form an accessory domain that assists in the polymerization of template-bound NTPs. The polymerization reaction is applicable to a variety of template sequences, and for well-behaved sequences proceeds with an average fidelity of 0.967 . This would be sufficient to support a genome length of about 30 nucleotides, although the ribozyme itself contains about 190 nucleotides. The ribozyme has a catalytic rate for NTP addition of at least $1.5 \mathrm{~min}^{-1}$, but its $K_{\mathrm{m}}$ is so high that, even in the presence of micromolar concentrations of oligonucleotides and millimolar concentrations of NTPs, it requires about $2 \mathrm{~h}$ to complete each NTP addition (Lawrence and Bartel 2003). The ribozyme 
operates best under conditions of high $\mathrm{Mg}^{2+}$ concentration, but becomes degraded under those conditions over $24 \mathrm{~h}$, by which time it has added no more than 14 NTPs (Johnston et al. 2001).

Further optimization of the polymerase ribozyme using highly sophisticated in vitro evolution techniques has led to additional improvements in its biochemical properties. By directly selecting for extension of an external primer on a separate template, Zaher and Unrau (2007) were able to improve the maximum length of template-dependent polymerization to $>20$ nucleotides, with a rate that is $\sim$ threefold faster than that of the parent for the first nine monomer additions and up to 75 -fold faster for additions beyond 10 nucleotides. In addition, although not rigorously quantitated, the new ribozyme displays significantly improved fidelity, particularly with respect to discrimination against $\mathrm{G} \bullet \mathrm{U}$ wobble pairs. It is this improved fidelity that appears to be the underlying source for the observed improvements in the maximum length of extension and the rate of polymerization.

A different RNA ligase ribozyme can operate on a separate RNA template in a largely sequence-general manner, and does so with a $K_{\mathrm{m}}$ that is at least 100-fold lower than that of the class-I-derived polymerase (McGinness and Joyce 2002). However, its catalytic rate is much lower as well, and it is unable to add more than a single NTP. Yet another RNA ligase ribozyme can operate on a separate template with the help of designed tertiary interactions that "clamp" the template-substrate complex to the ribozyme (Ikawa et al. 2004). But it too is a relatively slow catalyst that cannot add more than a single NTP.

A highly pessimistic view is that because there is no known polymerase ribozyme that combines all of the properties necessary to sustain its own replication, no such ribozyme is possible. A more balanced view is that RNA clearly is capable of greatly accelerating the template-dependent polymerization of nucleoside $5^{\prime}$-polyphosphates. Such catalytic RNAs can operate in a sequence-general manner and with reasonable fidelity. It seems only a matter of time (and likely considerable effort) before more robust polymerase ribozymes will be obtained. Nature did not have the opportunity to conduct carefully arranged evolution experiments using highly-purified reagents, but did have the luxury of much greater reaction volumes and much more time.

RNA Replication. Despite falling short of the ultimate goal of a general-purpose RNA polymerase ribozyme, a robust reaction system for RNA-catalyzed RNA replication has recently been shown. The system uses a pair of cross-replicating ligase ribozymes that each catalyze the formation of the other, using a mixture of four different substrate oligonucleotides (Lincoln and Joyce 2009). In reaction mixtures containing only these RNA substrates, $\mathrm{MgCl}_{2}$, and buffer, a small starting amount of ribozymes gives rise to many additional ribozymes through a process of RNA-catalyzed exponential amplification. Whenever the substrates become depleted, the replication process can be restarted and sustained indefinitely by replenishing the supply of substrates.

Because the substrates are recognized by the ribozymes through specific Watson-Crick pairing interactions, evolution experiments can be performed by providing a variety of substrates that have different sequences in these recognition regions and different corresponding sequences in the catalytic domain of the ribozyme. RNA replication was performed with a library of 144 possible substrate combinations, resulting in the emergence of a set of highly advantageous replicators that included recombinants which were not present at the start of the experiment. Until the advent of a general-purpose RNA polymerase ribozyme, the system of cross-replicating ligases offers the best platform to study the biochemical properties and evolutionary behavior of an all-RNA replicative system.

Nucleotide Biosynthesis. RNA replicase activity is probably not the only catalytic behavior that was essential for the existence of the RNA World. Maintaining an adequate supply of the four activated nucleotides would have been a top priority. Even if the prebiotic environment contained a large reservoir of these compounds, the reservoir would eventually become depleted, and some capacity for nucleotide biosynthesis would have been required.

Ribozymes have been obtained, through in vitro evolution, that catalyze some of the steps of nucleotide biosynthesis. Unrau and Bartel (1998), for example, developed a ribozyme that catalyzes a reaction between 4 -thiouracil and 5-phosphoribosyl-1-pyrophosphate (PRPP) to form 4-thiouridylate (Fig. 5A). The 4-thiouracil is provided free in solution and the PRPP is tethered to the $3^{\prime}$ end of the ribozyme. An optimized form of this ribozyme, containing 124 nucleotides, has an observed rate of $0.2 \mathrm{~min}^{-1}$ in the presence of $4 \mathrm{mM} 4$-thiouracil (Chapple et al. 2003). This is at least $10^{7}$-fold faster than the uncatalyzed rate of reaction, which is too slow to measure. Unrau and colleagues used a similar approach to develop two different ribozymes that catalyze the formation of 6-thioguanylate from 6-thioguanine and tethered PRPP (Lau et al. 2004), as well as a third guanylate synthase ribozyme that arose as an unanticipated consequence of a related in vitro evolution experiment (Lau and Unrau 2009). The first two guanylate synthase ribozymes are slightly larger and have about twofold higher catalytic efficiency compared 

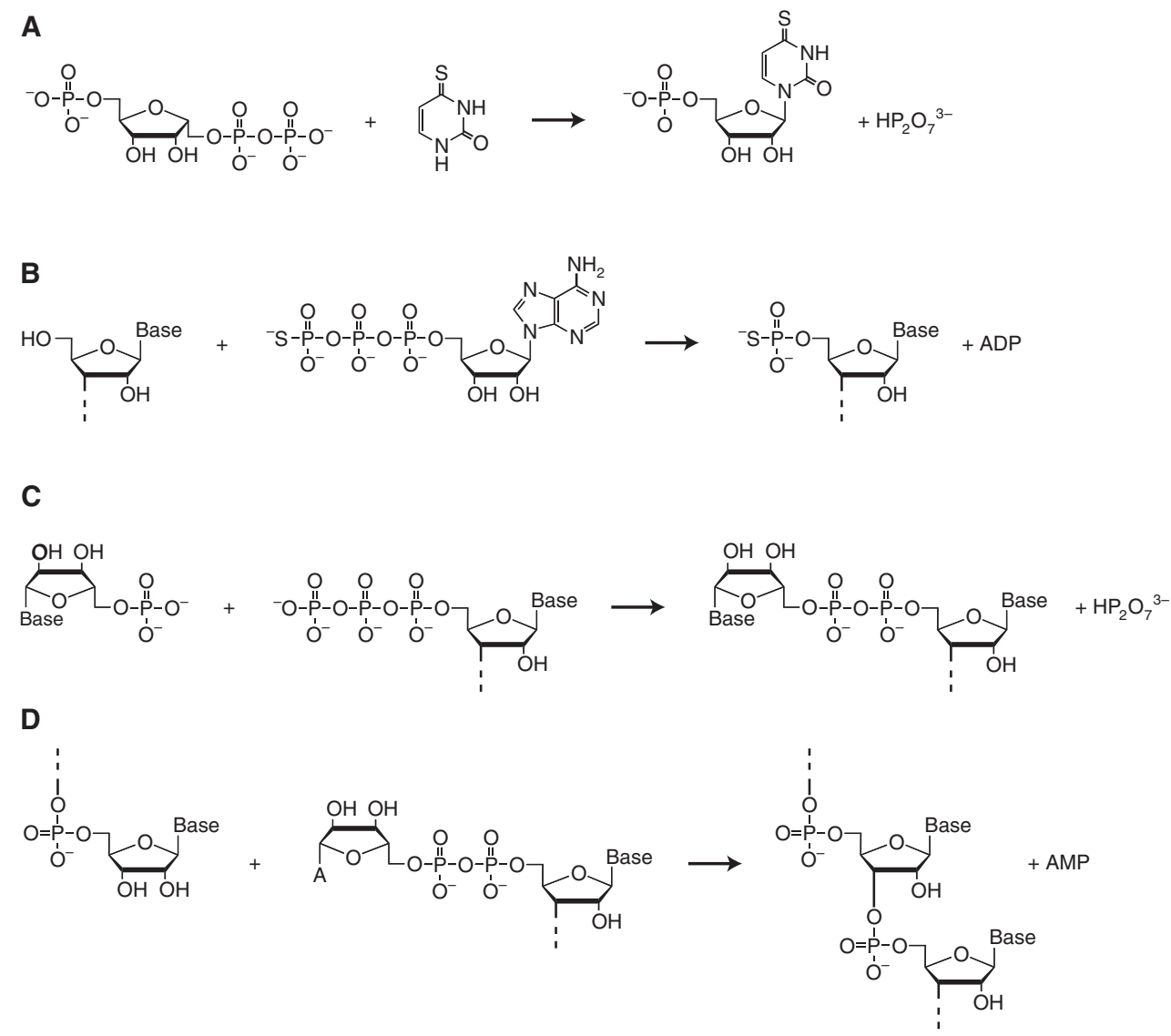

Figure 5. Known RNA-catalyzed reactions that are relevant to nucleotide biosynthesis. $(A)$ Formation of 4thiouridylate from free 4-thiouracil and ribozyme-tethered 5-phosphoribosyl-1-pyrophosphate. (B) 5'-phosphorylation of an oligonucleotide using $\gamma$-thio-ATP as the phosphate donor. $(C)$ Activation of a nucleoside $5^{\prime}$-phosphate by formation of a $5^{\prime}, 5^{\prime}$-pyrophosphate linkage. (D) Template-directed ligation of RNA driven by release of a $5^{\prime}, 5^{\prime}$-pyrophosphate-linked adenylate.

with the uridylate synthase ribozyme, although guanylate synthesis is expected to have a much higher uncatalyzed rate of reaction.

RNA-catalyzed synthesis of PRPP has not been shown, but a ribozyme has been obtained that catalyzes the $5^{\prime}$-phosphorylation of oligonucleotides using $\gamma$-thio-ATP as the phosphate donor (Lorsch and Szostak 1994) (Fig. 5B). The ribozyme shows a rate enhancement of about $10^{9}$ fold compared with the uncatalyzed rate of reaction. Once a nucleoside 5'-phosphate has been formed, it canphosphoryl be activated by another ribozyme that catalyzes the condensation of a nucleoside $5^{\prime}$-phosphate and a ribozyme-tethered nucleoside $5^{\prime}$-triphosphate (Huang and Yarus 1997) (Fig. 5C). This results in the formation of a $5^{\prime}, 5^{\prime}$-pyrophosphate linkage, which provides an activated nucleotide leaving group that can drive subsequent RNA-catalyzed, template-directed ligation of RNA (Hager and Szostak 1997) (Fig. 5D).
None of these four RNA-catalyzed reactions has precisely the right format for the corresponding reaction in a hypothetical nucleotide biosynthesis pathway in the RNA World. However, they show that RNA is capable of performing the relevant chemistry with substantial catalytic rate enhancement. It remains to be seen whether ribozymes can be developed that catalyze the formation of the fundamental building blocks of RNA, D-ribose and the four nucleotide bases, using starting materials that would have been abundant on the primitive Earth.

\section{AN "RNA-LATER" VIEW OF THE ORIGIN OF LIFE}

\subsection{Abiotic Synthesis of Nucleotides}

The RNA-first view of the origin of life proceeds from the assumption that pure B-D-nucleotides were available in some prebiotic pool. How close to such a pool could one 
hope to get without magic (or evolved enzymes) on the primitive Earth? Could one hope to achieve replication in a pool containing a more realistic mixture of organic molecules, including, of course, $B$-D-ribonucleotides? The synthesis of a nucleotide could occur in a number of ways. The simplest, conceptually, would be to synthesize a nucleoside base, couple it to ribose, and finally to phosphorylate the resulting nucleoside. However, a number of other routes are feasible, for example the assembly of the base on a preformed ribose or ribose phosphate, or the coassembly of the base and sugar-phosphate.

The classical prebiotic synthesis of sugars is by the polymerization of formaldehyde (the "formose" reaction). It yields a very complex mixture of products including only a small proportion of ribose (Mizuno and Weiss 1974). This reaction does not provide a reasonable route to the ribonucleotides. However, a number of more recent experimental findings, to some extent, address this deficiency.

The base-catalyzed aldomerization of glycoaldehyde phosphate in the presence of a half-equivalent of formaldehyde under strongly alkaline conditions gives a relatively simple mixture of tetrose- and pentose-diphosphates and hexose-triphosphates, of which ribose 2,4-diphosphate is the major component (Müller et al. 1990). Reactions of this kind proceed efficiently when $2 \mathrm{mM}$ solutions of substrates are incubated at room temperature and $\mathrm{pH} 9.5$ in the presence of layered hydroxides such as hydrotalcite (magnesium aluminum hydroxide) (Pitsch 1992; Pitsch et al. 1995a). The phosphates are absorbed between the positively charged layers of the mineral. The reaction proceeds under these milder conditions presumably because of the high concentration of substrates in the interlayer and because the positive charge on the metal hydroxide layers favors enolization of glycoaldehyde phosphate. A reaction between glycoaldehyde or glyceraldehyde and the amidotriphosphate ion provides an ingenious and prebiotically plausible route to glycoaldehyde phosphate and glyceraldehyde-2-phosphate, respectively, the two substrates in the above reactions (Krishnamurthy et al. 2000).

A number of other studies have addressed the problems presented by the lack of specificity of the formose reaction and by the instability of ribose. The $\mathrm{Pb}^{2+}$ ion is an excellent catalyst for the formose reaction and enables yields of the pentose sugars as high as 30\% to be achieved (Zubay 1998). Furthermore, it seems likely that ribose is almost exclusively the first pentose product of the reaction and that the other pentoses are formed from it by isomerization. Other recent studies have addressed the problem presented by the instability of ribose. The four pentose sugars, including ribose, are all strongly stabilized in the presence of borate ions or calcium borate minerals (Ricardo et al. 2004). However, the effect of borate on the progress of the formose reaction has not been reported.

Many sugars, including the four pentoses, react readily with cyanamide to form stable bicyclic amino-oxazolines (Sanchez and Orgel 1970) (Fig. 6A). Strikingly, the ribose derivative crystallizes readily from aqueous solution even when complex mixtures of related molecules, including a mixture of the amino-oxazoline derivatives of the other three pentose sugars, are present (Springsteen and Joyce 2004). The crystals are multiply twinned, each crystal containing many small domains of each of the two enantiomorphs. Thus the reaction of a mixture of racemic sugars with cyanamide followed by crystallization might stabilize ribose, segregate it from other sugars, and present it in enantiospecific microdomains. Much remains to be shown, but the reactions described above suggest that ribose synthesis, although still problematic, may not be the intractable problem it once seemed.

The synthesis of the nucleoside bases is one of the success stories of prebiotic chemistry. Adenine is formed with remarkable ease from ammonia and hydrogen cyanide (Orò 1961). This synthesis has been described as "the rock of the faith" by Stanley Miller. Reasonably plausible syntheses of the other purine bases and of the pyrimidines have also been described (Sanchez et al. 1967; Ferris et al. 1968; Robertson and Miller 1995; Orgel 2004b; Saladino et al. 2004). The coupling of the purine bases with ribose or ribose-phosphate has been achieved under mild conditions, but in relatively low yield (Fuller et al. 1972). The corresponding reaction with pyrimidines does not occur.

There is a different potential route for the prebiotic synthesis of pyrimidine nucleotides via arabinose aminooxazoline that first was explored nearly $40 \mathrm{yr}$ ago (Tapiero and Nagyvary 1971) and in recent years has begun to look very persuasive (Ingar et al. 2003; Anastasi et al. 2007; Powner et al. 2009). The earlier studies began with arabinose 3-phosphate, which, like arabinose and other sugars, reacts with cyanamide to give the corresponding aminooxazoline (Fig. 6B). This in turn reacts with cyanoacetylene to form a tricyclic intermediate that hydrolyzes to produce a mixture of cytosine arabinoside- $3^{\prime}$-phosphate and cytosine $2^{\prime}, 3^{\prime}$-cyclic phosphate.

Sutherland and colleagues (Powner et al. 2009) have taken this approach further by starting simply with glycoaldehyde and cyanamide, which in the presence of $1 \mathrm{M}$ phosphate at neutral $\mathrm{pH}$ gives 2-amino-oxazole in excellent yield (Fig. 6C). The phosphate both buffers and catalyzes the reaction, directing glycoaldehyde toward 2-aminooxazole, rather than a complex mixture of aldomerization products. Glyceraldehyde is then added, resulting in formation of the various pentose amino-oxazolines, including 
A

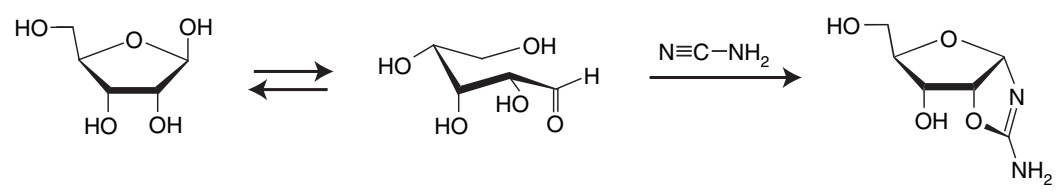

B<smiles>N#CCCC1OC2OC1C(OP(=O)([O-])O)C2O</smiles>

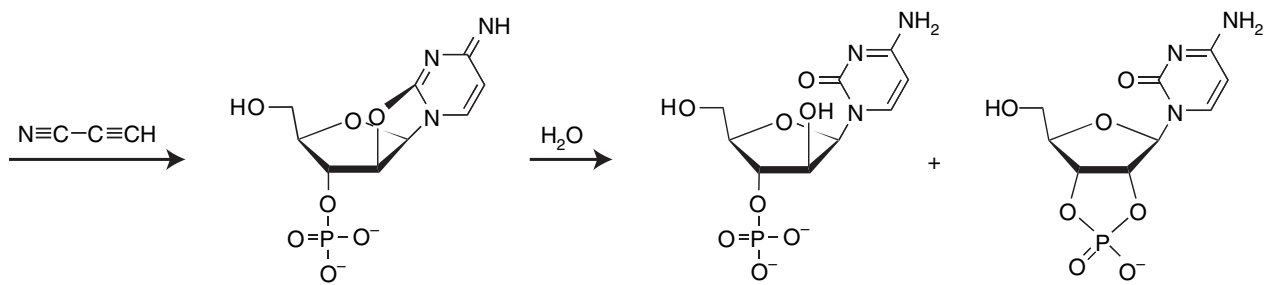

C

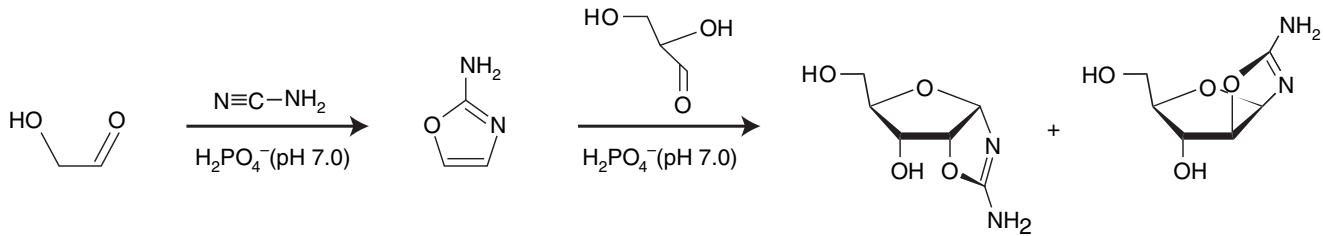

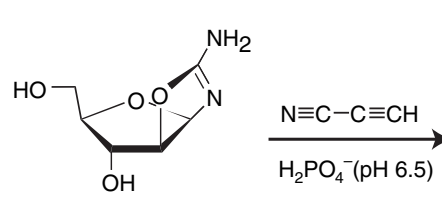<smiles>N=c1ccn2c(n1)OC1C(CO)OCC12O</smiles><smiles>Nc1ccn(C2OC(CO)C3OP(=O)([O-])OC32)c(=O)n1</smiles>

Figure 6. Potential prebiotic synthesis of pyrimidine nucleosides. (A) Reaction of ribose with cyanamide to form a bicyclic product, with cyanamide joined at both the anomeric carbon and 2-hydroxyl. (B) Analogous reaction of arabinose-3-phosphate to form a bicyclic product, which then reacts with cyanoacetylene to form a tricyclic intermediate that hydrolyzes to give a mixture of cytosine arabinoside- $3^{\prime}$-phosphate and cytosine $2^{\prime}, 3^{\prime}$-cyclic phosphate. (C) Reaction of glycoaldehyde with cyanamide in neutral phosphate buffer, followed by addition of glyceraldehyde, to form ribose and arabinose amino-oxazoline (and lesser amounts of the xylose and lyxose compounds). Arabinose amino-oxazoline then reacts with cyanoacetylene to give cytosine $2^{\prime}, 3^{\prime}$-cyclic phosphate as the major product.

the arabinose compound. Arabinose amino-oxazoline, in turn, can react with cyanoacetylene, also in phosphate buffer, to form cytosine $2^{\prime}, 3^{\prime}$-cyclic phosphate as the major product. Perhaps equally intriguing, although given less emphasis in these studies, is that reaction of arabinose amino-oxazoline with cyanoacetylene also gives a substantial yield of cytosine $2^{\prime}, 3^{\prime}$-cyclic-5'-bisphosphate, which is more amenable to being converted to an activated monomer that would be suitable for polymerization.
There has been significant progress, especially recently, concerning the synthesis of the nucleosides and nucleotides from prebiotic precursors in reasonable yield. However, the story remains incomplete because these syntheses still require temporally separated reactions using high concentrations of just the right reactants, and would be disrupted by the presence of other closely related compounds. The reactions channel material toward the desired products, but other fractionation processes must be discovered that 
provide the correct starting materials at the requisite time and place. This "preprebiotic" chemistry likely would involve a series of reactions catalyzed by minerals or metal ions, coupled with a series of subtle fractionations of nucleotide-like materials based on adsorption on minerals, selective complex formation, crystallization, etc.

Even minerals could not achieve on a macroscopic scale one desirable separation, the resolution of D-ribonucleotides from their L-enantiomers. This is a serious problem because experiments on template-directed synthesis using poly $(\mathrm{C})$ and the imidazolides of $\mathrm{G}$ suggest that the polymerization of the $\mathrm{D}$-enantiomer is strongly inhibited by the L-enantiomer (Joyce et al. 1984). This difficulty may not be insuperable; perhaps with a different mode of phosphate activation, the inhibition would be less severe. However, enantiomeric cross-inhibition is certainly a serious problem if life arose in a racemic environment.

It is possible that the locale for life's origins was not racemic, even though the global chemical environment contained nearly equal amounts of each pair of stereoisomers. There likely were biases in the inventory of compounds delivered to the Earth by comets and meteorites. For example, some carbonaceous chondrite meteorites contain a significant enantiomeric excess of $\mathrm{L}$-amino acids that are known to be indigenous to the meteorite (Engel and Macko 1997; Cronin and Pizzarello 1997; Pizzarello et al. 2003; Glavin and Dworkin 2009). These in turn could bias terrestrial syntheses, although the level of enantiomeric enrichment generally declines with successive chemical reactions. A special exception are a remarkable set of reactions and fractionation processes that amplify a slight chiral imbalance, even to the level of local homochirality (Kondepudi et al. 1990; Soai et al. 1995; Viedma 2005; Klussmann et al. 2006; Noorduin et al. 2008; Viedma et al. 2008). These systems have in common both a catalytic process for amplification of same-handed molecules and an inhibition process for suppression of opposite-handed molecules.

Some of the most appealing examples of chiral symmetry-breaking reactions involve saturating solutions of various amino acids that form an equilibrium between the liquid phase and solid phase. The solid phase consists of either racemic or enantiopure crystals, and the liquid phase reflects whatever enantiomeric excess exists at the eutectic point for the mixture. For some amino acids, such as serine and histidine, the enantiomeric excess at the eutectic is $>90 \%$ (Klussmann et al. 2006). This means that, starting from a small concentration imbalance of D- and L-isomers, the imbalance is amplified as both isomers enter the solid phase and the solution phase approaches the eutectic equilibrium. This and related near-equilibrium mechanisms (Noorduin et al. 2008; Viedma et al. 2008) could provide a means to achieve high enantiomeric enrichment in a local environment. This in turn could bias the production of ribose and the derived nucleotides.

Scientists interested in the origins of life seem to divide neatly into two classes. The first, usually but not always molecular biologists, believe that RNA must have been the first replicating molecule and that chemists are exaggerating the difficulties of nucleotide synthesis. They believe that a few more striking chemical "surprises" will establish that a pool of racemic mononucleotides could have formed on the primitive Earth, and that further experiments with different activating groups, minerals, and chiral amplification processes will solve the enantiomeric cross-inhibition problem. The second group of scientists are much more pessimistic. They believe that the de novo appearance of oligonucleotides on the abiotic Earth would have been a near miracle. Time will tell which is correct.

\subsection{Alternative Genetic Systems}

The problems that arise when one tries to understand how an RNAWorld could have arisen de novo on the primitive Earth are sufficiently severe that one must explore other possibilities. What kind of alternative genetic systems might have preceded the RNA World? How could they have "invented" the RNA World? These topics have generated a good deal of speculative interest and some relevant experimental data.

Eschenmoser and colleagues have undertaken a systematic study of the properties of analogs of nucleic acids in which ribose is replaced by some other sugar, or in which the furanose form of ribose is replaced by the pyranose form (Eschenmoser 1999) (Fig. 7B). Strikingly, polynucleotides based on the pyranosyl analog of ribose ( $p$-RNA) form Watson-Crick paired double helices that are more stable than RNA, and p-RNAs are less likely than the corresponding RNAs to form multiple-strand competing structures (Pitsch et al. 1993, 1995b, 2003). Furthermore, the helices twist much more gradually than those of standard nucleic acids, which should make it easier to separate strands of p-RNA during replication. Pyranosyl RNA appears to be an excellent choice as a genetic system; in some ways it seems an improvement compared with the standard nucleic acids. However, p-RNA does not interact with normal RNA to form base-paired double helices.

Most double-helical structures reported in the literature are characterized by a backbone with a six-atom repeat. Eschenmoser and colleagues made the surprising discovery that an RNA-like structure based on threose nucleotide analogs (TNA) (Fig. 7C), although it involves a five-atom repeat, can still form a stable double-helical structure with standard RNA (Schöning et al. 2000). This provides 
A

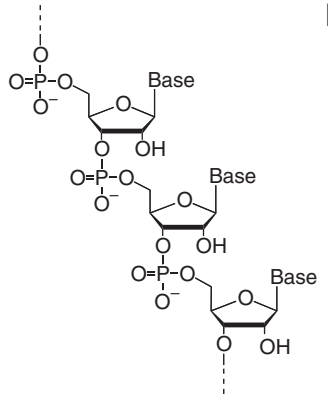

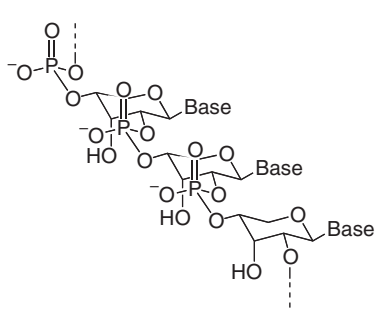

C

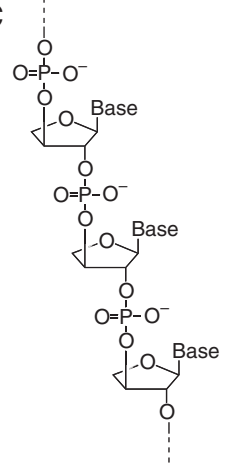

E

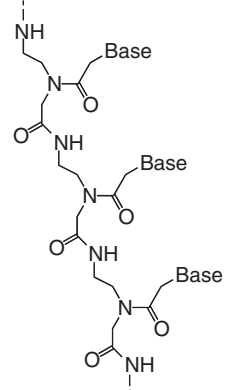

$\mathbf{F}$

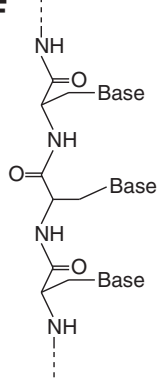

G

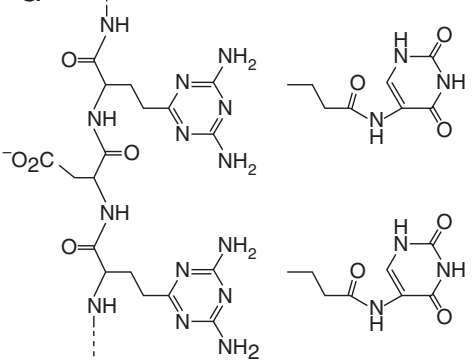

D

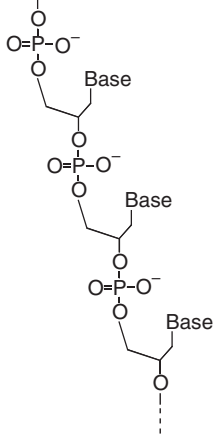

Figure 7. The structures of $(A)$ RNA; $(B)$ p-RNA; $(C)$ TNA; $(D)$ GNA; $(E)$ PNA; $(F)$ ANA; $(G)$ diaminotriazinetagged (left) and dioxo-5-aminopyrimidine-tagged (right) oligodipeptides; and $(H)$ tPNA. ANA contains a backbone of alternating D- and L-alanine subunits. The diaminotriazine tags are shown linked to a backbone of alternating L-aspartate and L-glutamate subunits; the dioxo-5-aminopyrimidine tags (shown unattached) can be linked similarly. tPNA is shown with a backbone of alternating L-cysteine and L-glutamate subunits.

an example of a pairing system based on a sugar that could be formed more readily than ribose: Tetroses are the unique products of the dimerization of glycoaldehyde, whereas pentoses are formed along with tetroses and hexoses from glycoaldehyde and glyceraldehyde. A structural simplification of Eschenmoser's threose nucleic acid has been achieved by Meggers and colleagues (Zhang et al. 2005). They replaced threose by its open chain analogue, glycol, in the backbone of TNA, resulting in glycol nucleic acid (GNA) (Fig. 7D). Complementary oligomers of GNA form antiparallel, double-helices with surprisingly high duplex stabilities.

Peptide nucleic acid (PNA) is another nucleic acid analog that has been studied extensively (Fig. 7E). It was discovered by Nielsen and colleagues in the context of research on antisense oligonucleotides (Egholm et al. 1992, 1993; Wittung et al. 1994). PNA is an uncharged, achiral analog of RNA or DNA in which the ribose-phosphate backbone of the nucleic acid is replaced by a backbone held together by amide bonds. PNA forms very stable double helices with complementary RNA or DNA. Work in the Orgel laboratory has shown that information can be transferred from PNA to RNA, or from RNA to PNA, in template-directed reactions, and that PNA/DNA chimeras are readily formed on either DNA or PNA templates (Schmidt et al. 1997a,b; Koppitz et al. 1998). Thus it seems that a transition from a PNA World to an RNA World is possible.

The alanyl nucleic acids (ANA) are interesting for a different reason. They are polypeptides formed from nucleo amino acids (Fig. 7F), but pairing structures can be formed only if the two enantiomers of their constituent $\alpha$-amino acids occur in a regular alternating sequence (Diederichsen 1996, 1997). Because abiotic syntheses of potentially chiral molecules would under almost all circumstances yield racemic products, pairing structures that can be formed from racemic mixtures are particularly attractive. The ANA-type backbone of alternating D- and L-amino acids could, in principle, support paired, double-stranded structures based on a variety of side-chain interactions.

Eschenmoser and colleagues have examined repeating homochiral dipeptide backbones that have either triazines or aminopyrimidines attached at alternating positions (Mittapalli et al. 2007a,b) (Fig. 7G). In this case, not only is the backbone a potential precursor to that of RNA, but also the bases have been replaced by potential precursors, 
such as 2,4-diaminotriazine $\left({ }^{\mathrm{T}} \mathrm{NN}\right)$, 2,4-dioxotriazine ( $\left.{ }^{\mathrm{T}} \mathrm{OO}\right)$, 2,4-diamino-5-aminopyrimidine $\left({ }^{\mathrm{AP}} \mathrm{NN}\right)$, and 2,4-dioxo-5-aminopyrimidine ( $\left.{ }^{\mathrm{AP}} \mathrm{OO}\right)$. Oligomers containing either ${ }^{\mathrm{T}} \mathrm{NN}$ or ${ }^{\mathrm{AP}} \mathrm{OO}$ subunits were found to pair strongly with complementary RNA, whereas oligomers containing either ${ }^{\mathrm{T}} \mathrm{OO}$ or ${ }^{\mathrm{AP}} \mathrm{NN}$ subunits did not. Not surprisingly, therefore, pairing between complementary substituted oligodipeptides of the same type (either oligo $\left[{ }^{\mathrm{T}} \mathrm{NN}\right] \bullet$ oligo $\left[{ }^{\mathrm{T}} \mathrm{OO}\right]$ or oligo $\left[{ }^{\mathrm{AP}} \mathrm{NN}\right] \bullet$ oligo $\left[{ }^{\mathrm{AP}} \mathrm{OO}\right]$ ) also was weak. However, cross-pairing between oligo $\left({ }^{\mathrm{T}} \mathrm{NN}\right)$ and oligo $\left({ }^{\mathrm{AP}} \mathrm{OO}\right)$ was robust (Mittapalli et al. 2007a). This raises the intriguing possibility that an informational polymer could have a mixed composition of ${ }^{\mathrm{T}} \mathrm{NN}$ and ${ }^{\mathrm{AP}} \mathrm{OO}$ subunits, which would direct the synthesis of an opposing strand that has a complementary sequence as well as a "complementary" backbone composition.

Even more radical are thioester peptide nucleic acids (tPNA) (Fig. 7H), containing a repeating dipeptide backbone with cysteine residues at alternating positions, which are transiently linked via a thioester to a nucleic acid base (Ura et al. 2009). The bases are in dynamic equilibrium between the solution and cysteine positions along the backbone. Occupancy of a base at a particular position is enhanced by the presence of the complementary base on the opposing strand. In this way the informational polymer can self-assemble in a template-directed manner, with mismatched bases exchanging rapidly and matched bases remaining thioesterified for an extended period of time. Perhaps genetic information could be propagated in such a system, although the fidelity of replication, and therefore the maximum number of informational subunits, is likely to be modest.

The studies described previously suggest that there are many ways of linking together the nucleotide bases into chains that are capable of forming base-paired double helices. It is not clear that it is much easier to synthesize the monomers of p-RNA, TNA, GNA, PNA, ANA, or tPNA than to synthesize the standard nucleotides. However, it is possible that a base-paired structure of this kind will be discovered that can be synthesized readily under prebiotic conditions. The properties of the ${ }^{\mathrm{T}} \mathrm{NN}$ - and ${ }^{\mathrm{AP}} \mathrm{OO}$-tagged oligodipeptides suggest that it may be fruitful to explore a broader range of potential precursors to RNA, changing the recognition elements as well as the backbone. A strong candidate for the first genetic material would be any informational macromolecule that is replicable in a sequencegeneral manner and derives from compounds that would have been abundant on the primitive Earth, and preferably has the ability to cross-pair with RNA.

The transition from an RNA-like World to the RNA World could take place in two ways. The transition might be continuous if the pre-RNA template could direct the synthesis of an RNA product with a complementary sequence. Such a transition, for example, from PNA to RNA, would preserve information. RNA could then act as a genetic material in a formerly PNAWorld. However, even if chimeras were involved in the transition, it is unlikely that the original function of a PNA catalyst could be retained throughout the transition because PNA and RNA have such different backbone structures. A direct and continuous transition from p-RNA to RNA would not be possible because p-RNA does not form complementary double helices with RNA, but this limitation does not apply to TNA and GNA.

The second type of transition can be described as a genetic takeover. A pre-existing self-replicating system evolves, for its own selective advantage, a mechanism for synthesizing and polymerizing the components of a completely different genetic system, and is taken over by it. Cairns-Smith (1982) has proposed that the first genetic system was inorganic, perhaps a clay, and that it "invented" a self-replicating system based on organic monomers. However, he clearly recognized the possibility of one organic genetic material replacing another (Cairns-Smith and Davies 1977). Genetic takeover does not require any structural relationship between the polymers of the two genetic systems. It suggests the possibility that the original genetic system may have been unrelated to nucleic acids.

The hypothesis of a genetic material completely different from nucleic acids has one enormous advantage-it opens up the possibility of using very simple, easily synthesized prebiotic monomers in place of nucleotides. However, it also raises two new and difficult questions. Which prebiotic monomers are plausible candidates as the components of a replicating system? Why would an initial genetic system invent nucleic acids once it had evolved sufficient synthetic know-how to generate molecules as complex as nucleotides?

A number of prebiotic monomers that might have made up a simple genetic material have already been suggested. They include hydroxy acids (Weber 1987), amino acids (Orgel 1968; Zhang et al. 1994), phosphomonoesters of polyhydric alcohols (Weber 1989), aminoaldehydes (Nelsestuen 1980), and molecules containing two sulfhydryl groups (Schwartz and Orgel 1985). The list could be expanded almost indefinitely. The discussion here concerns a small class of these monomers that appear to be particularly attractive in the light of recent work on enzyme mechanisms.

There is accumulating evidence that several enzymes that make or break phosphodiester bonds have two or three metal ions at their active sites (Cooperman et al. 1992; Sträter et al. 1996). In the case of the editing site for phosphodiester hydrolysis in the Klenow fragment of Escherichia coli DNA polymerase I, no other functional groups 
of the enzyme come close to the phosphodiester bond that is cleaved. This has led to the suggestion that the major role of the enzyme is to act as scaffolding on which to hang metal ions in precisely determined positions (Beese and Steitz 1991; Steitz 1998). A similar suggestion has been made for ribozymes on the basis of both indirect and direct evidence (Freemont et al. 1988; Yarus 1993; Steitz and Steitz 1993; Shan et al. 1999, 2001; Stahley and Strobel 2005).

Perhaps these observations can be extended to suggest that, if informational polymers preceded RNA, they may also have been dependent on metal ions for their catalytic activity. If so, the range of prebiotic monomers that needs to be considered is greatly reduced. In addition to the functional groups that react to form the backbone, the monomers must have carried metal-binding functional groups. If the metal ions involved were divalent ions such as $\mathrm{Mg}^{2+}$ and $\mathrm{Ca}^{2+}$, the side groups are likely to have been carboxylate or phosphate groups. If transition metal ions were involved, sulfhydryl groups and possibly imidazole derivatives are likely to have been important.

Prebiotic monomers suitable for building polymers that bind $\mathrm{Mg}^{2+}$ or $\mathrm{Ca}^{2+}$ include aspartic acid, glutamic acid, and serine phosphate among biologically important amino acids. $ß$-amino acids, such as isoglutamic acid, hydroxydicarboxylic acids, such as $\alpha$-hydroxysuccinic acid, and hydroxytricarboxylic acids, such as citric acid, are other possible candidates. A polymer containing D-aspartic acid, $\mathrm{L}$-aspartic acid, and glycine as its subunits is typical of potentially informational co-polymers that might, in the presence of divalent metal ions, both replicate and function as a catalyst. Transition-metal ions might play a corresponding role for polymers containing cysteine or homocysteine. The present challenge is to show replication, or at least information transfer in template-directed synthesis, in some such system.

What selective advantage could a simpler, metabolically competent system derive from the synthesis of oligonucleotides? This is a baffling question. Most arguments that come to mind do not stand up to detailed analysis. If, for example, one postulates that nucleotides were first synthesized as parts of cofactors such as DPN, one must explain why the particular heterocyclic bases and sugars were chosen. Even if one supposes that among the many "experiments" in secondary metabolism performed by early organisms one happened by accident on a pair of complementary nucleotides that could form a replicating polymer, one must still explain how polymerization subsequently contributed to the success of the "inventor." Could oligonucleotides, by hybridization, have functioned at first as selective "glues" for tying pairs of macromolecules together? Could RNA have been invented by one organism as "antisense" against the genome of another?
The discussion so far, even though highly speculative, is still conservative in overall outlook. It supposes that the original information-accumulating system that led to the evolution of life on Earth was either RNA or some linear copolymer that replicated in an aqueous environment in much the same way as RNA. There remains a lingering doubt that the discussion is not on the right track at all; maybe the original system was not an organic copolymer (Cairns-Smith 1982), or maybe it replicated in a nonaqueous environment and RNA is an adaptation that permitted invasion of the oceans. Perhaps systems of high complexity can develop without any need for a genome in the usual sense (Dyson 1982; Kauffman 1986; Wächtershäuser 1988; De Duve 1991; Eschenmoser 2007). Perhaps ...

Laboratory simulations of prebiotic chemistry are dependent on organic chemistry and can only explore the kinds of reactions understood by organic chemists. A good deal is known about reactions in aqueous solution, but less about reactions at the interface between water and inorganic solids. Very little is known about reactions in systems in which inorganic solids are depositing from aqueous solutions containing organic material. It is hard to see how speculative schemes involving heterogeneous aqueous systems can be tested until much more is known about the underlying branches of chemistry.

\section{CONCLUDING REMARKS}

After contemplating the possibility of self-replicating ribozymes emerging from pools of random polynucleotides and recognizing the difficulties that must have been overcome for RNA replication to occur in a realistic prebiotic soup, the challenge must now be faced of constructing a realistic picture of the origin of the RNA World. The constraints that must have been met in order to originate a selfsustained evolving system are reasonably well understood. One can sketch out a logical order of events, beginning with prebiotic chemistry and ending with DNA/proteinbased life. However, it must be said that the details of this process remain obscure and are not likely to be known in the near future.

The presumed RNAWorld should be viewed as a milestone, a plateau in the early history of life on Earth. So too, the concept of an RNA World has been a milestone in the scientific study of life's origins. While this concept does not explain how life originated, it has helped to guide scientific thinking and has served to focus experimental efforts. Further progress will depend primarily on new experimental results, as chemists, biochemists, and molecular biologists work together to address problems concerning molecular replication, ribozyme enzymology, and RNAbased cellular processes. 


\section{ACKNOWLEDGMENTS}

This work was supported by research grant NNX07AJ23G from the National Aeronautics and Space Administration. Previous versions of this article, which were published in the First (1993), Second (1999), and Third (2006) Editions of The RNA World, were coauthored by Leslie Orgel, who died on October 27, 2007. Many portions of the text have not been changed in the current edition because they remain an accurate reflection of current scientific understanding. The contributions of Leslie Orgel to this work and to the scientific literature of the origins of life are gratefully acknowledged.

\section{REFERENCES}

Acevedo OL, Orgel LE. 1987. Non-enzymatic transcription of an oligodeoxynucleotide 14 residues long. J Mol Biol 197: 187-193.

Anastasi C, Crowe MA, Sutherland JD. 2007. Two-step potentially prebiotic synthesis of $\alpha$-D-cytidine-5' -phosphate from D-glyceraldehyde3-phosphate. J Am Chem Soc 129: 24-25.

Ban N, Nissen P, Hansen J, Moore PB, Steitz TA. 2000. The complete atomic structure of the large ribosomal subunit at $2.4 \AA$ resolution. Science 289: 905-920.

Bartel DP, Szostak JW. 1993. Isolation of new ribozymes from a large pool of random sequences. Science 261: 1411-1418.

Been MD, Cech TR. 1988. RNA as an RNA polymerase: Net elongation of an RNA primer catalyzed by the Tetrahymena ribozyme. Science 239: $1412-1416$.

Beese LS, Steitz TA. 1991. Structural basis for the $3^{\prime}-5^{\prime}$ exonuclease activity of Escherichia coli DNA polymerase I: A two metal ion mechanism. EMBO J 10: 25-33.

Cairns-Smith AG. 1982. Genetic takeover and the mineral origins of life. Cambridge University Press, Cambridge.

Cairns-Smith AG, Davies CJ. 1977. The design of novel replicating polymers. In Encyclopaedia of ignorance (eds. Duncan R., Weston-Smith M.), pp. 391-403. Pergamon Press, Oxford.

Cech TR. 1986. A model for the RNA-catalyzed replication of RNA. Proc Natl Acad Sci 83: 4360-4363.

Chapple KE, Bartel DP, Unrau PJ. 2003. Combinatorial minimization and secondary structure determination of a nucleotide synthase ribozyme. RNA 9: 1208-1220.

Cooperman BS, Baykov AA, Lahti R. 1992. Evolutionary conservation of the active site of soluble inorganic pyrophosphatase. Trends Biochem Sci 17: 262-266.

Crick FHC. 1968. The origin of the genetic code. J Mol Biol 38: 367-379.

Cronin JR, Pizzarello S. 1997. Enantiomeric excesses in meteoritic amino acids. Science 275: 951-955.

De Duve C. 1991. Blueprint for a cell: The nature and origin of life. Neil Patterson Publishers, Burlington, North Carolina.

Diederichsen U. 1996. Pairing properties of alanyl peptide nucleic acids containing an amino acid backbone with alternating configuration. Angew Chemie 35: 445-448.

Diederichsen U. 1997. Alanyl PNA: Evidence for linear band structures based on guanine-cytosine base pairs. Angew Chemie 36: 1886-1889.

Ding ZP, Kawamura K, Ferris JP. 1996. Oligomerization of uridine phosphorimidazolides on montmorillonite: A model for the prebiotic synthesis of RNA on minerals. Orig Life Evol Biosph 26: 151-171.

Doudna JA, Szostak JW. 1989. RNA-catalysed synthesis of complementary-strand RNA. Nature 339: 519-522.

Dyson FJ. 1982. A model for the origin of life. J Mol Evol 18: 344-350.

Egholm M, Buchardt O, Christensen L, Behrens C, Freier SM, Driver DA, Berg RH, Kim SK, Norden B, Nielson PE. 1993. PNA hybridizes to complementary oligonucleotides obeying the Watson-Crick hydrogen-bonding rules. Nature 365: 566-568.

Egholm M, Buchardt O, Nielson PE, Berg RH. 1992. Peptide nucleic acids (PNA). Oligonucleotide analogues with an achiral peptide backbone. J Am Chem Soc 114: 1895-1897.

Eigen M. 1971. Selforganization of matter and the evolution of biological macromolecules. Naturwiss 58: 465-523.

Eigen M, Schuster P. 1977. The hypercycle: A principle of natural selforganization. Part A: Emergence of the hypercycle. Naturwiss 64: $541-565$.

Eigen M, McCaskill J, Schuster P. 1988. Molecular quasi-species. J Phys Chem 92: 6881-6891.

Ekland EH, Bartel DP. 1996. RNA-catalysed RNA polymerization using nucleoside triphosphates. Nature 382: 373-376.

Ekland EH, Szostak JW, Bartel DP. 1995. Structurally complex and highly active RNA ligases derived from random RNA sequences. Science 269: 364-370.

Emilsson GM, Nakamura S, Roth A, Breaker RR. 2003. Ribozyme speed limits. RNA 9: 907-918.

Engel M, Macko S. 1997. Isotopic evidence for extraterrestrial nonracemic amino acids in the Murchison meteorite. Nature 389: $265-268$.

Erman JE, Hammes GG. 1966. Relaxation spectra of ribonuclease. V. The interaction of ribonuclease with cytidine $2^{\prime}: 3^{\prime}$-cyclic phosphate. J Am Chem Soc 88: 5614-5617.

Eschenmoser A. 1999. Chemical etiology of nucleic acid structure. Science 284: 2118-2124.

Eschenmoser A. 2007. On a hypothetical generational relationship between $\mathrm{HCN}$ and constituents of the reductive citric acid cycle. Chem Biodivers 4: $554-573$.

Ferris JP. 2002. Montmorillonite catalysis of 30-50 mer oligonucleotides: Laboratory demonstration of potential steps in the origin of the RNA world. Orig Life Evol Biosph 32: 311-332.

Ferris JP. 2006. Montmorillonite-catalyzed formation of RNA oligomers: The possible role of catalysis in the origins of life. Phil Trans $R$ Soc B 361: $1777-1786$.

Ferris JP, Ertem G. 1993. Montmorillonite catalysis of RNA oligomer formation in aqueous solution. A model for the prebiotic formation of RNA. J Am Chem Soc 115: 12270-12275.

Ferris JP, Sanchez RA, Orgel LE. 1968. Studies in prebiotic synthesis. III. Synthesis of pyrimidines from cyanoacetylene and cyanate. J Mol Biol 33: $693-704$

Ferris JP, Hill AR, Liu R, Orgel LE. 1996. Synthesis of long prebiotic oligomers on mineral surfaces. Nature 381: 59-61.

Ferris JP, Joshi PC, Wang KJ, Miyakawa S, Huang W. 2004. Catalysis in prebiotic chemistry: Application to the synthesis of RNA oligomers. Adv Space Res 33: 100-105.

Freemont PS, Friedman JM, Beese LS, Sanderson MR, Steitz TA. 1988. Cocrystal structure of an editing complex of Klenow fragment with DNA. Proc Natl Acad Sci 85: 8924-8928.

Fujita Y, Furuta H, Ikawa Y. 2009. Tailoring RNA modular units on a common scaffold: A modular ribozyme with a catalytic unit for $\beta$-nicotinamide mononucleotide-activated RNA ligation. RNA 15: 877-888.

Fuller WD, Sanchez RA, Orgel LE. 1972. Studies in prebiotic synthesis. VI. Synthesis of purine nucleosides. J Mol Biol 67: 25-33.

Gilbert W. 1986. The RNA world. Nature 319: 618.

Glavin DP, Dworkin JP. 2009. Enrichment of the amino acid L-isovaline by aqueous alteration on CI and CM meteorite parent bodies. Proc Natl Acad Sci 106: 5487-5492.

Guerrier-Takada C, Gardiner K, Marsh T, Pace N, Altman S. 1983. The RNA moiety of ribonuclease $\mathrm{P}$ is the catalytic subunit of the enzyme. Cell 35: 849-857.

Hager AJ, Szostak JW. 1997. Isolation of novel ribozymes that ligate AMP-activated RNA substrates. Chem Biol 4: 607-617. 
Handschuh GJ, Lohrmann R, Orgel LE. 1973. The effect of $\mathrm{Mg}^{2+}$ and $\mathrm{Ca}^{2+}$ on urea-catalyzed phosphorylation reactions. J Mol Evol 2: $251-262$.

Huang F, Yarus M. 1997. Versatile 5' phosphoryl coupling of small and large molecules to an RNA. Proc Natl Acad Sci 94: 8965-8969.

Huang W, Ferris JP. 2003. Synthesis of 35-40 mers of RNA oligomers from unblocked monomers. A simple approach to the RNA world. Chem Commun 12: $1458-1459$.

Huang W, Ferris JP. 2006. One-step, regioselective synthesis of up to 50 -mers of RNA oligomers by montmorillonite catalysis. J Am Chem Soc 128: 8914-8919.

Ikawa Y, Tsuda K, Matsumura S, Inoue T. 2004. De novo synthesis and development of an RNA enzyme. Proc Natl Acad Sci 101: 13750-13755.

Ingar AA, Luke RWA, Hayter BR, Sutherland JD. 2003. Synthesis of a cytidine ribonucleotide by stepwise assembly of the heterocycle on a sugar phosphate. Chembiochem 4: 504-507.

Inoue T, Orgel LE. 1981. Substituent control of the poly(C)-directed oligomerization of guanosine 5'-phosphoroimidazolide. J Am Chem Soc 103: $7666-7667$.

Inoue T, Orgel LE. 1982. Oligomerization of (guanosine $5^{\prime}$-phosphor)2-methylimidazolide on poly(C). J Mol Biol 162: 204-217.

Inoue T, Orgel LE. 1983. A nonenzymatic RNA polymerase model. Science 219: 859-862.

Inoue T, Joyce GF, Grzeskowiak K, Orgel LE, Brown JM, Reese CB. 1984. Template-directed synthesis on the pentanucleotide CpCpGpCpC. J Mol Biol 178: 669-676.

Jaeger L, Wright MC, Joyce GF. 1999. A complex ligase ribozyme evolved in vitro from a group I ribozyme domain. Proc Natl Acad Sci 96: $14712-14717$.

James KD, Ellington AD. 1999. The fidelity of template-directed oligonucleotide ligation and the inevitability of polymerase function. Orig Life Evol Biosph 29: 375-390.

Johnston WK, Unrau PJ, Lawrence MS, Glasner ME, Bartel DP. 2001. RNA-catalyzed RNA polymerization: Accurate and general RNAtemplated primer extension. Science 292: 1319-1325.

Joshi PC, Aldersley MF, Delano JW, Ferris JP. 2009. Mechanism of montmorillonite catalysis in the formation of RNA oligomers. J Am Chem Soc 131: 13369-13374.

Joyce GF. 1987. Non-enzymatic template-directed synthesis of informational macromolecules. Cold Spring Harbor Symp Quant Biol 52: $41-51$.

Joyce GF. 1989. RNA evolution and the origins of life. Nature 338: $217-224$.

Joyce GF. 2002. The antiquity of RNA-based evolution. Nature 418: 214-221.

Joyce GF, Orgel LE. 1986. Non-enzymic template-directed synthesis on RNA random copolymers: Poly $(\mathrm{C}, \mathrm{G})$ templates. J Mol Biol 188: 433-441.

Joyce GF, Orgel LE. 1993. Prospects for understanding the origin of the RNA world. In The RNA world (eds. Gesteland R.F., Atkins J.F.), pp. 1-25. Cold Spring Harbor Laboratory Press, Cold Spring Harbor, NY.

Joyce GF, Schwartz AW, Miller SL, Orgel LE. 1987. The case for an ancestral genetic system involving simple analogues of the nucleotides. Proc Natl Acad Sci 84: 4398-4402.

Joyce GF, Visser GM, van Boeckel CAA, van Boom JH, Orgel LE, van Westrenen J. 1984. Chiral selection in poly(C)-directed synthesis of oligo(G). Nature 310: 602-604.

Kanavarioti A, Monnard PA, Deamer DW. 2001. Eutectic phases in ice facilitate nonenzymatic nucleic acid synthesis. Astrobiology 1: 271-281.

Kauffman SA. 1986. Autocatalytic sets of proteins. J Theor Biol 119: 1-24.

Kawamura K, Ferris JP. 1994. Kinetic and mechanistic analysis of dinucleotide and oligonucleotide formation from the $5^{\prime}$-phosphorimidazolide of adenosine on $\mathrm{Na}^{+}$-montmorillonite. J Am Chem Soc 116: 7564-7572.

Kawamura K, Ferris JP. 1999. Clay catalysis of oligonucleotide formation: Kinetics of the reaction of the $5^{\prime}$-phosphorimidazolides of nucleotides with the non-basic heterocycles uracil and hypoxanthine. Orig Life Evol Biosph 29: 563-591.

Khorana HG. 1961. Some recent developments in the chemistry of phosphate esters of biological interest, pp. 126-141. Wiley \& Sons, New York.

Klussmann M, Iwamura H, Mathew SP, Wells Jr DH, Pandya U, Armstrong A, Blackmond DG. 2006. Thermodynamic control of asymmetric amplification in amino acid catalysis. Nature 441: 621-623.

Kondepudi DK, Kaufman RJ, Singh N. 1990. Chiral symmetry breaking in sodium chlorate crystallization. Science 250: 975-976.

Koppitz M, Nielsen PE, Orgel LE. 1998. Formation of oligonucleotidePNA-chimeras by template-directed ligation. J Am Chem Soc 120: 4563-4569.

Kozlov IA, Politis PK, Van Aerschot A, Busson R, Herdewijn P, Orgel LE. 1999. Nonenzymatic synthesis of RNA and DNA oligomers on hexitol nucleic acid templates: the importance of the A structure. J Am Chem Soc 121: 2653-2656.

Kozlov IA, Zielinski M, Allart B, Kerremans L, Van Aerschot A, Busson R, Herdewijn P, Orgel LE. 2000. Nonenzymatic template-directed reactions on altritol oligomers, preorganized analogues of oligonucleotides. Chem Eur J 6: 151-155.

Krishnamurthy R, Guntha S, Eschenmoser A. 2000. Regioselective $\alpha$-phosphorylation of aldoses in aqueous solution. Angew Chemie 39: 2281-2285.

Kruger K, Grabowski PJ, Zaug AJ, Sands J, Gottschling DE, Cech TR. 1982. Self-splicing RNA: Autoexcision and autocyclization of the ribosomal RNA intervening sequence of Tetrahymena. Cell 31: 147-157.

Kurz M, Göbel K, Hartel C, Göbel MW. 1997. Nonenzymatic oligomerization of ribonucleotides on guanosine-rich templates: Suppression of the self-pairing of guanosine. Angew Chemie 36: 842-845.

Kurz M, Göbel K, Hartel C, Göbel MW. 1998. Acridine-labeled primers as tools for the study of nonenzymatic RNA oligomerization. Helv Chim Acta 81: 1156-1180.

Lau MWL, Cadieux KEC, Unrau PJ. 2004. Isolation of fast purine nucleotide synthase ribozymes. J Am Chem Soc 126: 15686-15693.

Lau MWL, Unrau PJ. 2009. A promiscuous ribozyme promotes nucleotide synthesis in addition to ribose chemistry. Chem Biol 16: 815-825.

Lawrence MS, Bartel DP. 2003. Processivity of ribozyme-catalyzed RNA polymerization. Biochemistry 42: 8748-8755.

Lewin R. 1986. RNA catalysis gives fresh perspective on the origin of life. Science 231: 545-546.

Lincoln TA, Joyce GF. 2009. Self-sustained replication of an RNA enzyme. Science 323: 1229-1232.

Lohrmann R. 1975. Formation of nucleoside 5'-polyphosphates from nucleotides and trimetaphosphate. J Mol Evol 6: 237-252.

Lohrmann R. 1977. Formation of nucleoside $5^{\prime}$-phosphoramidates under potentially prebiological conditions. J Mol Evol 10: 137-154.

Lohrmann R, Orgel LE. 1973. Prebiotic activation processes. Nature 244: $418-420$.

Lohrmann R, Orgel LE. 1976. Template-directed synthesis of high molecular weight polynucleotide analogues. Nature 261: 342-344.

Lorsch J, Szostak JW. 1994. In vitro evolution of new ribozymes with polynucleotide kinase activity. Nature 371: 31-36.

McCaskill JS. 1984a. A stochastic theory of molecular evolution. Biol Cybernetics 50: 63-73.

McCaskill JS. 1984b. A localization threshold for macromolecular quasispecies from continuously distributed replication rates. J Chem Phys 80: $5194-5202$.

McGinness KE, Joyce GF. 2002. RNA-catalyzed RNA ligation on an external RNA template. Chem Biol 9: 297-307.

Mittapalli GK, Osornio YM, Guerrero MA, Reddy KR, Krishnamurthy R, Eschenmoser A. 2007a. Mapping the landscape of potentially primordial informational oligomers: Oligodipeptides tagged with 2,4disubstituted 5-aminopyrimidines as recognition elements. Angew Chemie 46: 2478-2484. 
Mittapalli GK, Reddy KR, Xiong H, Munoz O, Han B, De Riccardis F, Krishnamurthy R, Eschenmoser A. 2007b. Mapping the landscape of potentially primordial informational oligomers: Oligodipeptides and oligodipeptoids tagged with triazines as recognition elements. Angew Chemie 46: 2470-2477.

Miyakawa S, Ferris JP. 2003. Sequence- and regioselectivity in the montmorillonite-catalyzed synthesis of RNA. J Am Chem Soc 125: $8202-8208$.

Mizuno T, Weiss AH. 1974. Synthesis and utilization of formose sugars. Adv Carbohyd Chem Biochem 29: 173-227.

Mohr SC, Thach RE. 1969. Application of ribonuclease $T_{1}$ to the synthesis of oligoribonucleotides of defined base sequence. J Biol Chem 244: $6566-6576$.

Monnard PA, Kanavarioti A, Deamer DW. 2003. Eutectic phase polymerization of activated ribonucleotide mixtures yields quasi-equimolar incorporation of purine and pyrimidine nucleobases. J Am Chem Soc 125: 13734-13740.

Müller D, Pitsch S, Kittaka A, Wagner E, Wintner CE, Eschenmoser A. 1990. Chemie von $\alpha$-aminonitrilen. Aldomerisierung von Glykolaldehydphosphat zu racemischen hexose-2,4,6-triphosphaten und (in gegenwart von formaldehyd) racemischen pentose-2,4-diphosphaten: rac.-allose-2,4,6-triphosphat und rac.-ribose-2,4-diphosphat sind die reaktionshauptprodukte. Helv Chim Acta 73: 1410-1468.

Narlikar GJ, Herschlag D. 1997. Mechanistic aspects of enzymatic catalysis: Lessons from comparison of RNA and protein enzymes. Annu Rev Biochem 66: 19-59.

Nelsestuen GL. 1980. Origin of life: Consideration of alternatives to proteins and nucleic acids. J Mol Evol 15: 59-72.

Nissen P, Hansen J, Ban N, Moore PB, Steitz TA. 2000. The structural basis of ribosome activity in peptide bond synthesis. Science 289: 920-930.

Noorduin WL, Izumi T, Millemaggi A, Leeman M, Meekes H, Van Enckevort WJP, Kellogg RM, Kaptein B, Vlieg E, Blackmond DG. 2008. Emergence of a single solid chiral state from a nearly racemic amino acid derivative. J Am Chem Soc 130: 1158-1159.

Orgel LE. 1968. Evolution of the genetic apparatus. J Mol Biol 38: $381-393$.

Orgel LE. 1989. Was RNA the first genetic polymer? In Evolutionary tinkering in gene expression (eds. Grunberg-Manago M., Clark B.F.C., Zachau H.G.), pp. 215-224. Plenum, London.

Orgel LE. 2004a. Prebiotic chemistry and the origin of the RNA world. Crit Rev Biochem Mol Biol 39: 99-123.

Orgel LE. 2004b. Prebiotic adenine revisited: Eutectics and photochemistry. Orig Life Evol Biosph 34: 361-369.

Orò J. 1961. Mechanism of synthesis of adenine from hydrogen cyanide under plausible primitive earth conditions. Nature 191: 1193-1194.

Osterberg R, Orgel LE, Lohrmann R. 1973. Further studies of ureacatalyzed phosphorylation reactions. J Mol Evol 2: 231-234.

Pace NR, Marsh TL. 1985. RNA catalysis and the origin of life. Orig Life Evol Biosph 16: 97-116.

Pitsch S. 1992. "Zur chemie von glykolaldehyd-phosphat: Seine bildung aus oxirancarbonitril und seine aldomerisierumg zu den (racemischen) pentose-2,4-diphosphaten und hexose-2,4,6-triphosphaten." Ph.D. Thesis, ETH, Zürich.

Pitsch S, Eschenmoser A, Gedulin B, Hui S, Arrhenius G. 1995a. Mineral induced formation of sugar phosphates. Orig Life Evol Biosph 25: 297-334.

Pitsch S, Krishnamurthy R, Bolli M, Wendeborn S, Holzner A, Minton M, Lesueur C, Schlönvogt I, Jaun B, Eschenmoser A. 1995b. Pyranosyl-RNA ('p-RNA'): Base-pairing selectivity and potential to replicate. Helv Chim Acta 78: 1621-1635.

Pitsch S, Wendeborn S, Jaun B, Eschenmoser A. 1993. Why pentose- and not hexose-nucleic acids? Pyranosyl-RNA ('p-RNA'). Helv Chim Acta 76: $2161-2183$.

Pitsch S, Wendeborn S, Krishnamurthy R, Holzner A, Minton M, Bolli M, Miculka C, Windhab N, Micura R, Stanek M, et al. 2003. Pentopyranosyl oligonucleotide systems. 9th communication. The B-D- ribopyranosyl- $\left(4^{\prime} \rightarrow 2^{\prime}\right)$-oligonucleotide system ('pyranosyl-RNA'): Synthesis and resumé of base-pairing properties. Helv Chim Acta 86: $4270-4363$

Pizzarello S, Zolensky M, Turk KA. 2003. Nonracemic isovaline in the Murchison meteorite: Chiral distribution and mineral association. Geochim Cosmochim Acta 67: 1589-1595.

Prabahar KJ, Ferris JP. 1997. Adenine derivatives as phosphate-activating groups for the regioselective formation of $3^{\prime}, 5^{\prime}$-linked oligoadenylates on montmorillonite: Possible phosphate-activating groups for the prebiotic synthesis of RNA. J Am Chem Soc 119: 4330-4337.

Powner MW, Gerland B, Sutherland JD. 2009. Synthesis of activated pyrimidine ribonucleotides in prebiotically plausible conditions. Nature 459: 239-242.

Reimann R, Zubay G. 1999. Nucleoside phosphorylation: A feasible step in the prebiotic pathway to RNA. Orig Life Evol Biosph 29: 229-247.

Ricardo A, Carrigan MA, Olcott AN, Benner SA. 2004. Borate minerals stabilize ribose. Science 303: 196.

Robertson MP, Ellington AD. 1999. In vitro selection of an allosteric ribozyme that transduces analytes into amplicons. Nature Biotechnol 17: $62-66$.

Robertson MP, Miller SL. 1995. An efficient prebiotic synthesis of cytosine and uracil. Nature 375: 772-774.

Robertson MP, Scott WG. 2007. The structural basis of ribozymecatalyzed RNA assembly. Science 315: 1549-1553.

Rogers J, Joyce GF. 2001. The effect of cytidine on the structure and function of an RNA ligase ribozyme. RNA 7: 395-404.

Rohatgi R, Bartel DP, Szostak JW. 1996a. Kinetic and mechanistic analysis of nonenzymatic, template-directed oligoribonucleotide ligation. $J$ Am Chem Soc 118: 3332-3339.

Rohatgi R, Bartel DP, Szostak JW. 1996b. Nonenzymatic, templatedirected ligation of oligoribonucleotides is highly regioselective for the formation of $3^{\prime}-5^{\prime}$ phosphodiester bonds. J Am Chem Soc 118: $3340-3344$

Saladino R, Crestini C, Costanzo G, DiMauro E. 2004. Advances in the prebiotic synthesis of nucleic acids bases: Implications for the origin of life. Curr Org Chem 8: 1425-1443.

Sanchez RA, Orgel LE. 1970. Studies in prebiotic synthesis. V. Synthesis and photoanomerization of pyrimidine nucleosides. J Mol Biol 47: 531-543.

Sanchez RA, Ferris JP, Orgel LE. 1967. Studies in prebiotic synthesis. II. Synthesis of purine precursors and amino acids from cyanoacetylene and cyanate. J Mol Biol 30: 223-253.

Sawai H, Kuroda K, Hojo T. 1988. Efficient oligoadenylate synthesis catalyzed by uranyl ion complex in aqueous solution. In Nucleic acids research symposium series (ed. Hayatsu H.), vol. 19, pp. 5-7. IRL Press Limited, Oxford.

Shechner DM, Grant RA, Bagby SC, Koldobskaya Y, Piccirilli JA, Bartel DP. 2009. Crystal structure of the catalytic core of an RNA polymerase ribozyme. Science 326: 1271-1275.

Schmidt JG, Christensen L, Nielsen PE, Orgel LE. 1997a. Information transfer from DNA to peptide nucleic acids by template-directed syntheses. Nucleic Acids Res 25: 4792-4796.

Schmidt JG, Nielsen PE, Orgel LE. 1997b. Information transfer from peptide nucleic acids to RNA by template-directed syntheses. Nucleic Acids Res 25: 4797-4802.

Schöning K, Scholz P, Guntha S, Wu X, Krishnamurthy R, Eschenmoser A. 2000. Chemical etiology of nucleic acid structure: The $\alpha$-threofuranosyl- $\left(3^{\prime} \rightarrow 2^{\prime}\right)$ oligonucleotide system. Science 290: 1347-1351.

Schrum JP, Ricardo A, Krishnamurthy M, Blain JC, Szostak JW. 2009. Efficient and rapid template-directed nucleic acid copying using $2^{\prime}$-amino-2', 3'-dideoxyribonucleoside- $5^{\prime}$-phosphorimidazolide monomers. J Am Chem Soc 131: 14560-14570.

Schuster P, Swetina J. 1988. Stationary mutant distributions and evolutionary optimization. Bull Math Biol 50: 635-660.

Schwartz AW, Orgel LE. 1985. Template-directed synthesis of novel, nucleic acid-like structures. Science 228: 585-587. 
Shan S, Kravchuk AV, Piccirilli JA, Herschlag D. 2001. Defining the catalytic metal ion interactions in the Tetrahymena ribozyme reaction. Biochemistry 40: 5161-5171.

Shan S, Yoshida A, Sun S, Piccirilli JA, Herschlag D. 1999. Three metal ions at the active site of the Tetrahymena group I ribozyme. Proc Natl Acad Sci 96: 12299-12304.

Shapiro R. 1984. The improbability of prebiotic nucleic acid synthesis. Orig Life Evol Biosph 14: 565-570.

Sharp PA. 1985. On the origin of RNA splicing and introns. Cell 42: 397-400.

Sleeper HL, Orgel LE. 1979. The catalysis of nucleotide polymerization by compounds of divalent lead. J Mol Evol 12: 357-364.

Soai K, Shibata T, Morioka H, Choji K. 1995. Asymmetric autocatalysis and amplification of enantiomeric excess of a chiral molecule. Nature 378: $767-768$.

Springsteen G, Joyce GF. 2004. Selective derivatization and sequestration of ribose from a prebiotic mix. J Am Chem Soc 126: 9578-9583.

Stahley MR, Strobel SA. 2005. Structural evidence for a two-metal-ion mechanism of group I intron splicing. Science 309: 1587-1590.

Steitz TA. 1998. A mechanism for all polymerases. Nature 391: 231-232.

Steitz TA, Moore PB. 2003. RNA, the first macromolecular catalyst: The ribosome is a ribozyme. Trends Biochem Sci 28: 411-418.

Steitz TA, Steitz JA. 1993. A general two-metal-ion mechanism for catalytic RNA. Proc Natl Acad Sci 90: 6498-6502.

Sträter N, Lipscomb WN, Klabunde T, Krebs B. 1996. Two-metal ion catalysis in enzymatic acyl- and phosphoryl-transfer reactions. Angew Chemie 35: 2024-2055.

Strobel SA, Ortoleva-Donnelly L. 1999. A hydrogen-bonding triad stabilizes the chemical transition state of a group I ribozyme. Chem Biol 6: $153-165$.

Szabó P, Scheuring I, Czárán T, Szathmáry E. 2002. In silico simulations reveal that replicators with limited dispersal evolve towards higher efficiency and fidelity. Nature 420: 340-343.

Sulston J, Lohrmann R, Orgel LE, Todd MH. 1968. Nonenzymatic synthesis of oligoadenylates on a polyuridylic acid template. Proc Natl Acad Sci 59: 726-733.

Tapiero CM, Nagyvary J. 1971. Prebiotic formation of cytidine nucleotides. Nature 231: 42-43.

Unrau PJ, Bartel DP. 1998. RNA-catalysed nucleotide synthesis. Nature 395: $260-263$.

Ura Y, Beierle JM, Leman LJ, Orgel LE, Ghadiri MR. 2009. Selfassembling sequence-adaptive peptide nucleic acids. Science 325: $73-77$.

Viedma C. 2005. Chiral symmetry breaking during crystallization: Complete chiral purity induced by nonlinear autocatalysis and recycling. Phys Rev Lett 94: 065504.
Viedma C, Ortiz JE, de Torres T, Izumi T, Blackmond DG. 2008. Evolution of solid phase homochirality for a proteinogenic amino acid. JAm Chem Soc 130: 15274-15275.

Wächtershäuser G. 1988. Before enzymes and templates: Theory of surface metabolism. Microbiol Rev 52: 452-484.

Wang KJ, Ferris JP. 2001. Effect of inhibitors on the montmorillonite claycatalyzed formation of RNA: Studies on the reaction pathway. Orig Life Evol Biosph 31: 381-402.

Weber AL. 1987. The triose model: Glyceraldehyde as a source of energy and monomers for prebiotic condensation reactions. Orig Life Evol Biosph 17: 107-119.

Weber AL. 1989. Model of early self-replication based on covalent complementarity for a copolymer of glycerate-3-phosphate and glycerol-3-phosphate. Orig Life Evol Biosph 19: 179-186.

Weiner AM, Maizels N. 1987. tRNA-like structures tag the $3^{\prime}$ ends of genomic RNA molecules for replication: Implications for the origin of protein synthesis. Proc Natl Acad Sci 84: 7383-7387.

Wimberly BT, Brodersen DE, Clemons WMJr, Morgan-Warren RJ, Carter AP, Vonrhein C, Hartsch T, Ramakrishnan V. 2000. Structure of the 30S ribosomal subunit. Nature 407: 327-338.

Wittung P, Nielsen PE, Buchardt O, Egholm M, Norden B. 1994. DNAlike double helix formed by peptide nucleic acid. Nature 368: 561-563.

Woese C. 1967. The genetic code, pp. 179-195. Harper and Row, New York.

Wu T, Orgel LE. 1992a. Nonenzymatic template-directed synthesis on oligodeoxycytidylate sequences in hairpin oligonucleotides. J Am Chem Soc 114: 317-322.

Wu T, Orgel LE. 1992b. Nonenzymatic template-directed synthesis on hairpin oligonucleotides. II. Templates containing cytidine and guanosine residues. J Am Chem Soc 114: 5496-5501.

Yarus M. 1993. How many catalytic RNAs? Ions and the Cheshire Cat conjecture. FASEB J 7: 31-39.

Yusupov M, Yusupova G, Baucom A, Lieberman K, Earnest TN, Cate JH, Noller HF. 2001. Crystal structure of the ribosome at $5.5 \AA$ resolution. Science 292: 883-896.

Zhang S, Lockshin C, Cook R, Rich A. 1994. Unusually stable beta-sheet formation in an ionic self-complementary oligopeptide. Biopolymers 34: $663-672$.

Zhang L, Peritz A, Meggers E. 2005. A simple glycol nucleic acid. J Am Chem Soc 127: 4174-4175.

Zielinski WS, Orgel LE. 1985. Oligomerization of activated derivatives of $3^{\prime}$-amino-3'-deoxyguanosine on $\operatorname{poly}(\mathrm{C})$ and $\operatorname{poly}(\mathrm{dC})$ templates. Nucleic Acids Res 13: 2469-2484.

Zielinski WS, Orgel LE. 1987. Oligomerization of dimers of $3^{\prime}$-amino-3'-deoxy-nucleotides (GC and CG) in aqueous solution. Nucleic Acids Res 13: 1699-1715.

Zubay G. 1998. Studies on the lead-catalyzed synthesis of aldopentoses. Orig Life Evol Biosph 28: 13-26. 


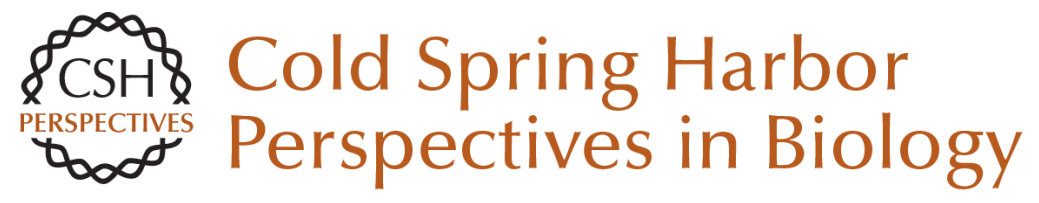

\section{The Origins of the RNA World}

Michael P Robertson and Gerald F Joyce

Cold Spring Harb Perspect Biol 2012; doi: 10.1101/cshperspect.a003608 originally published online April 28, 2010

\section{Subject Collection RNA Worlds}

Alternate RNA Structures

Marie Teng-Pei Wu and Victoria D'Souza

Approaches for Understanding the Mechanisms

of Long Noncoding RNA Regulation of Gene

Expression

Patrick McDonel and Mitchell Guttman

Principles and Practices of Hybridization Capture

Experiments to Study Long Noncoding RNAs That

Act on Chromatin

Matthew D. Simon and Martin Machyna

Linking RNA Sequence, Structure, and Function

on Massively Parallel High-Throughput

Sequencers

Sarah K. Denny and William J. Greenleaf

Extensions, Extra Factors, and Extreme

Complexity: Ribosomal Structures Provide

Insights into Eukaryotic Translation

Melanie Weisser and Nenad Ban

Nascent RNA and the Coordination of Splicing with Transcription

Karla M. Neugebauer

Combining Mass Spectrometry (MS) and Nuclear

Magnetic Resonance (NMR) Spectroscopy for Integrative Structural Biology of Protein-RNA

Complexes

Alexander Leitner, Georg Dorn and Frédéric H.-T. Allain
Structural Biology of Telomerase

Yaqiang Wang, Lukas Susac and Juli Feigon

Structural Insights into Nuclear pre-mRNA

Splicing in Higher Eukaryotes

Berthold Kastner, Cindy L. Will, Holger Stark, et al.

What Are 3' UTRs Doing?

Christine Mayr

\section{Single-Molecule Analysis of Reverse}

Transcriptase Enzymes

Linnea I. Jansson and Michael D. Stone

\section{CRISPR Tools for Systematic Studies of RNA}

Regulation

Jesse Engreitz, Omar Abudayyeh, Jonathan Gootenberg, et al.

Relating Structure and Dynamics in RNA Biology Kevin P. Larsen, Junhong Choi, Arjun Prabhakar, et al.

Beyond DNA and RNA: The Expanding Toolbox of

Synthetic Genetics Alexander I. Taylor, Gillian Houlihan and Philipp Holliger

For additional articles in this collection, see http://cshperspectives.cshlp.org/cgi/collection/

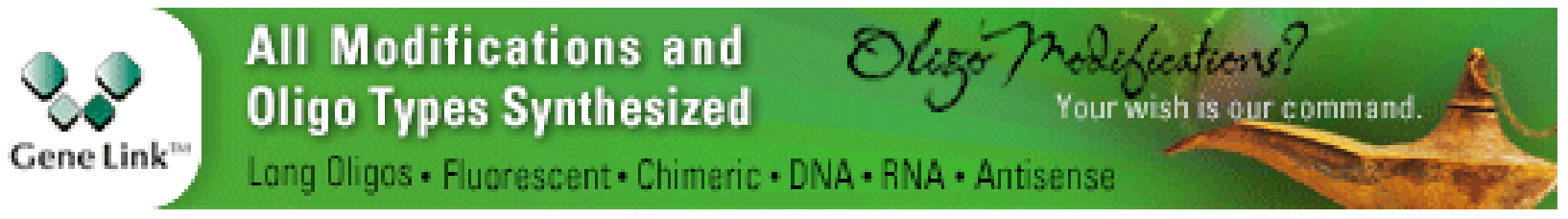


Discovering and Mapping the Modified Nucleotides That Comprise the Epitranscriptome of mRNA

Bastian Linder and Samie R. Jaffrey
Structural Basis of Nuclear pre-mRNA Splicing:

\section{Lessons from Yeast}

Clemens Plaschka, Andrew J. Newman and Kiyoshi Nagai

For additional articles in this collection, see http://cshperspectives.cshlp.org/cgi/collection/

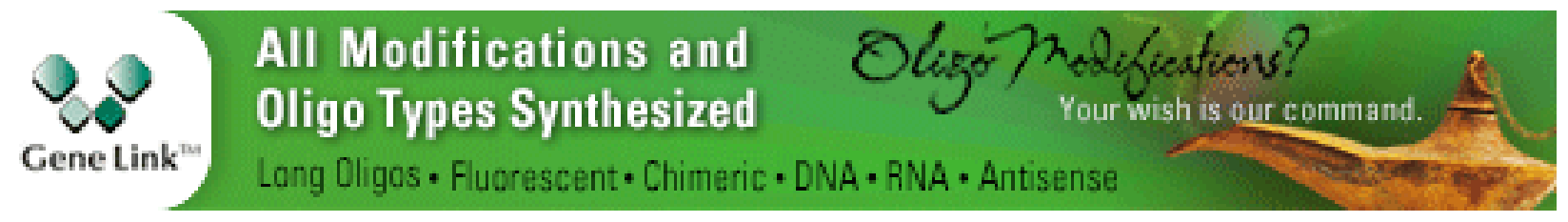

Copyright (C) 2012 Cold Spring Harbor Laboratory Press; all rights reserved 